$$
\begin{aligned}
& \text { أثز الخصائص البصرية الفيزياوية للفضاء العائلي } \\
& \text { على درجة الخيار للفعاليات اليومية ــ المسكن المعاصر في مدينة الموصل حالة دئة دراسية لإسية }
\end{aligned}
$$

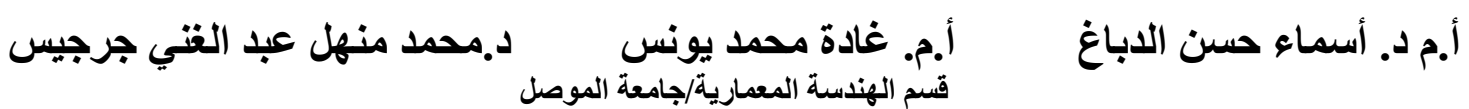

الخلاصة

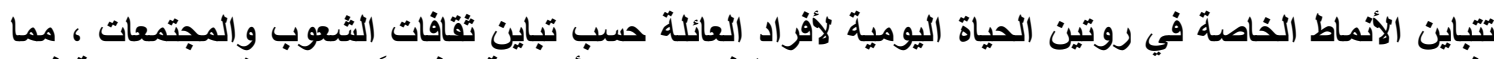

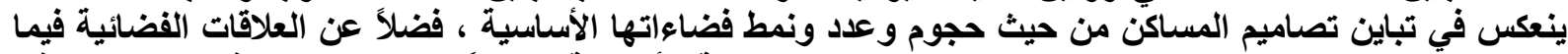

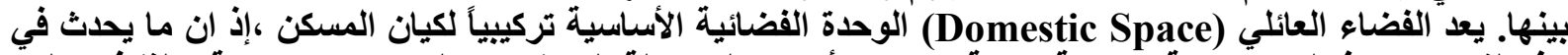

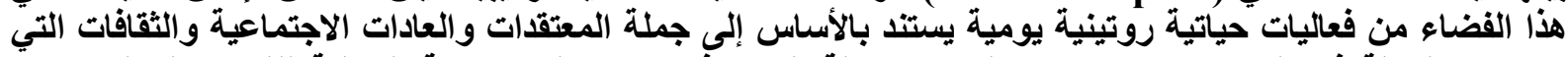

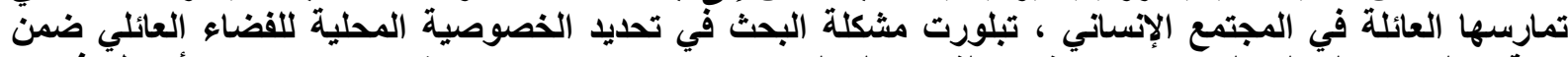

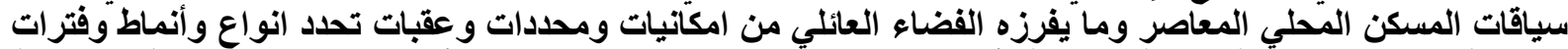

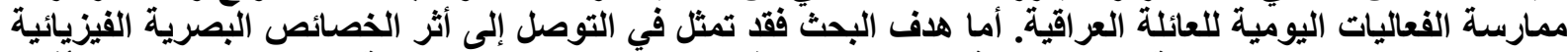

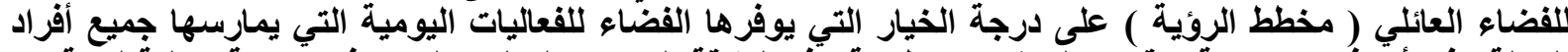

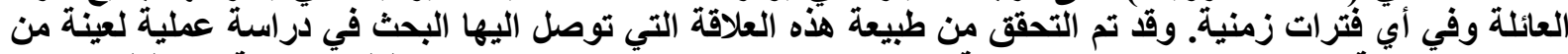

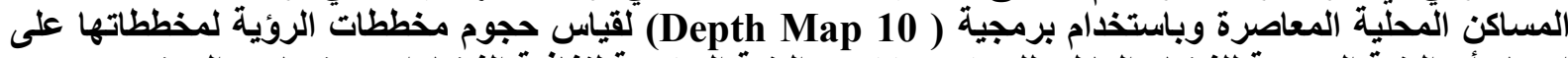

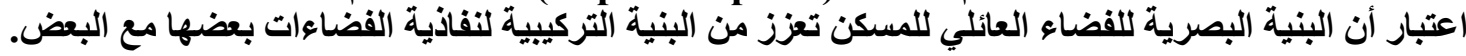

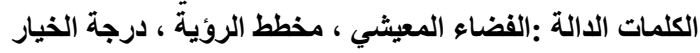

\title{
The effect of Visual Characteristics of Domestic Spaces on Level of Choice for Daily Activity Routine - Evaluate Local Houses in Mosul City
}

\author{
A.H. Aldabagh Gh. M. Younis M.M.A. Jarjees \\ Architecture Engineering Dept. University of Mosul
}

\begin{abstract}
The specific patterns of daily activities routine in houses for each society varies according to differences of its culture, believes, rituals and traditions . which reflects the varity of houses type and physical characteristics of size , number of fundamental living spaces. Houses we live are not only physical structures containing our daily routines activities, they are integral part of our cultural system, then Domestic space is spatial boundary that frame our living activities along the day according to our culture and behavioral codes that determines the way space is used and claimed within the home. This article aim to represent the properties of domestic space within local houses . its limitation , prospects ,obstructions and barriers for daily living activities ,Building in general and house in particular, information control achieved through visual field are a part of privacy - territory living activities, which regulate the amount and level of interpersonal interaction between inhabitants. The purpose of this research is to analyze Isovist graph for domestic spaces by applying Depth map software in order to get reflection of visual physical characteristic on level of choice daily activities for all members of Mosul family. The study concludes that the visual structure of domestic spaces enhanced spatial permeability structure and affected of the capability of activity choice .
\end{abstract}

Keyword: Domestic space, ,Isovist graph ,choice.

$$
\text { قبل: } 2015 \text { - } 3 \text { - } 16
$$$$
\text { 'ستلم: } 2014 \text { - } 2 \text { - } 16
$$ 
Domestic Space:

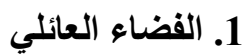

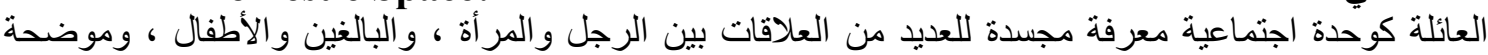

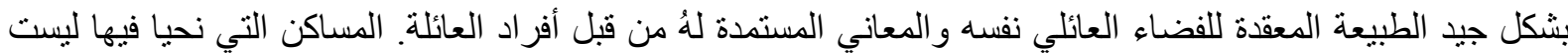

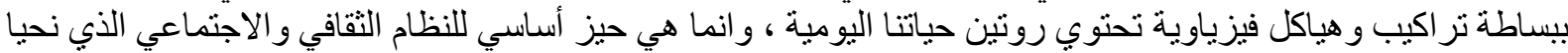

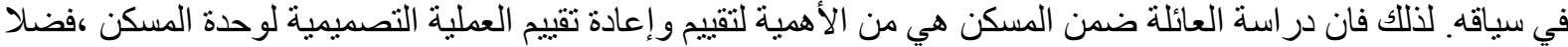

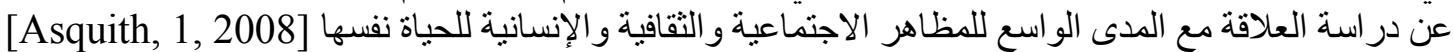

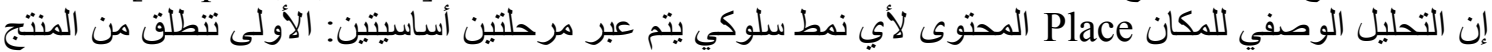

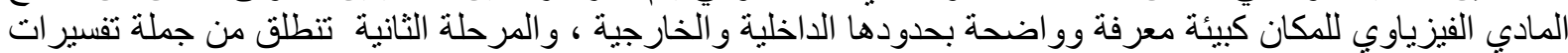

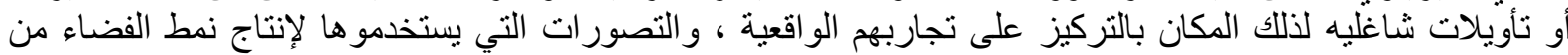

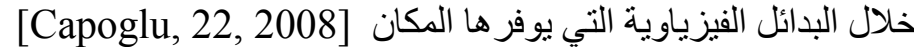

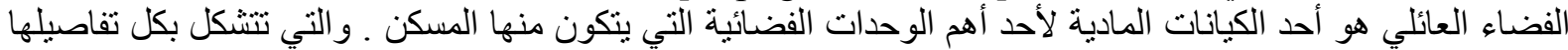

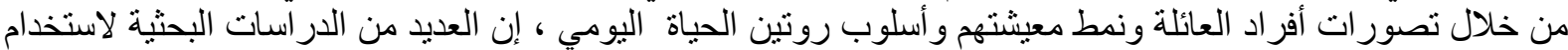

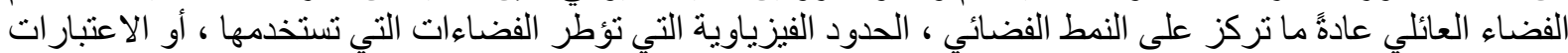

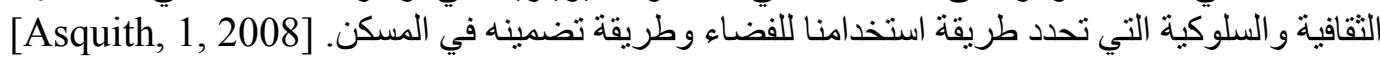

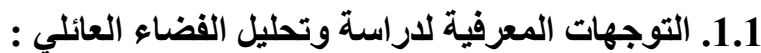

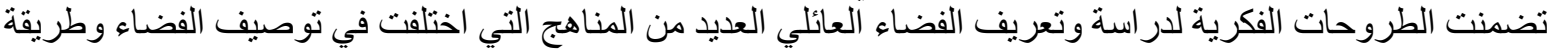

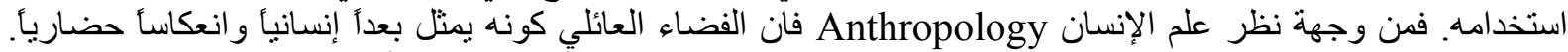

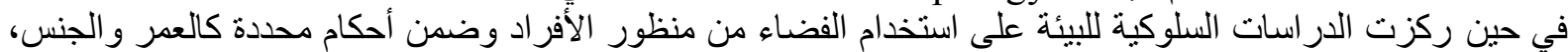

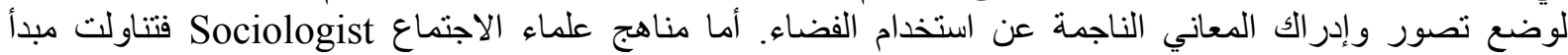

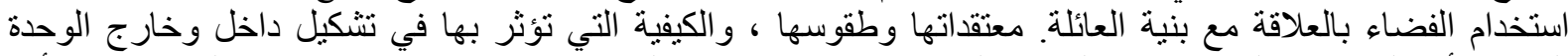

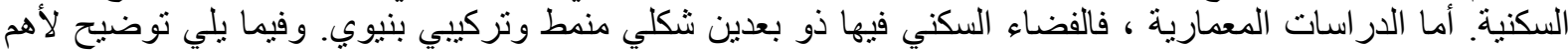

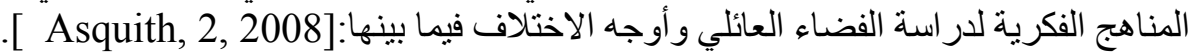

2.1.1 - 2.1 الدراسات الانثرويولوجية للفضاء العائلي

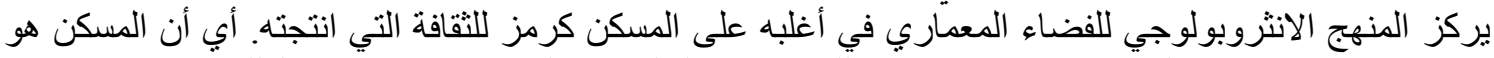

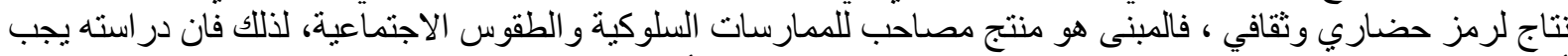

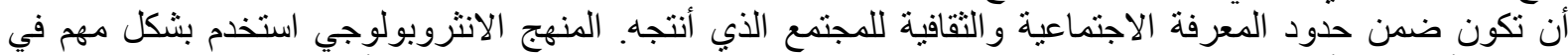

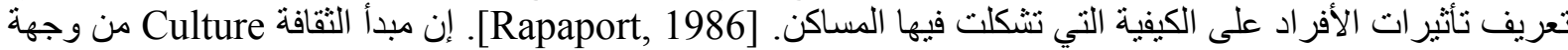

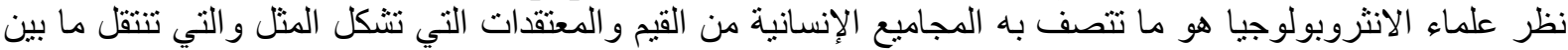

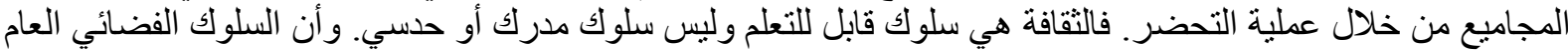

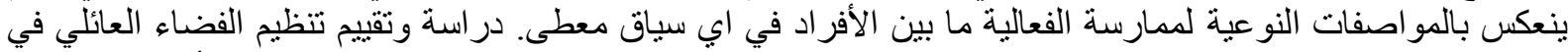

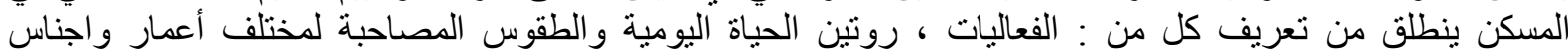

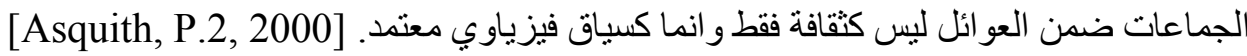

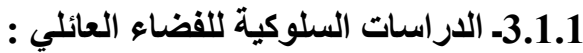

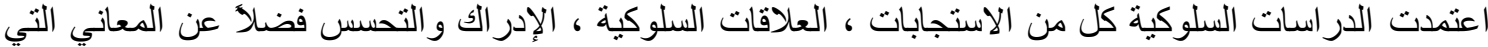

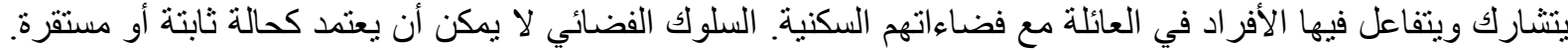

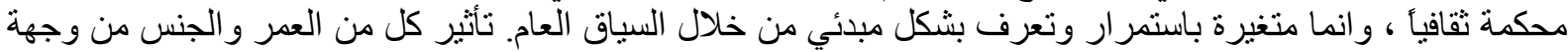

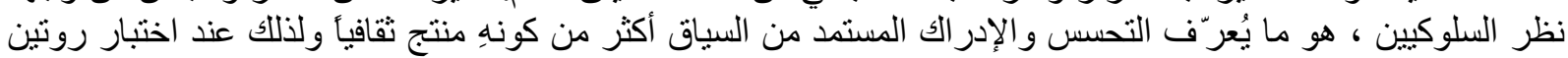

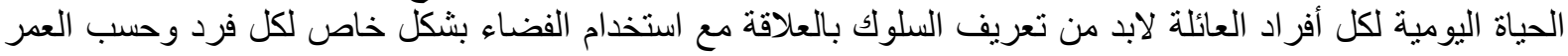
و الجنس. [Asquith, P.3, 2008] 


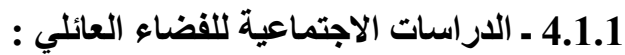

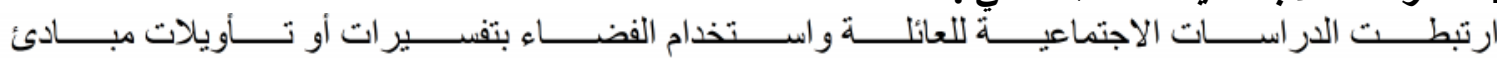

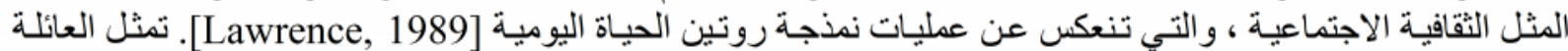

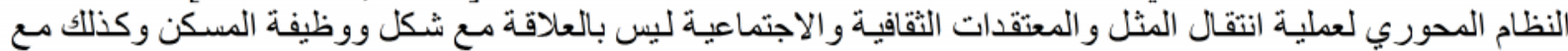

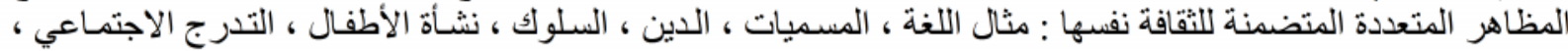

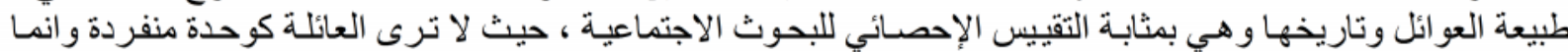

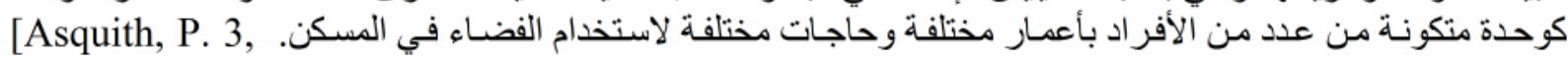
2008]

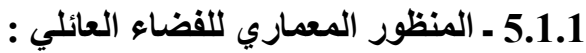

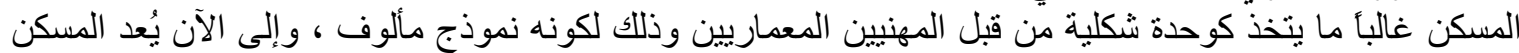

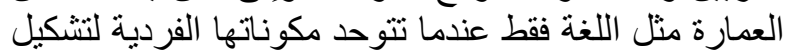

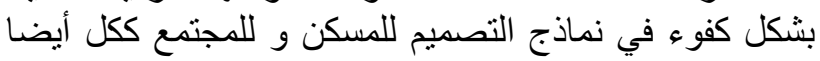

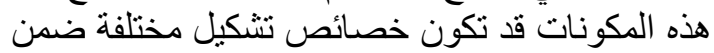

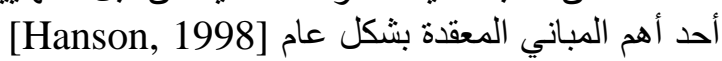

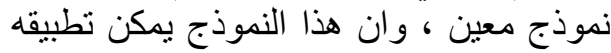

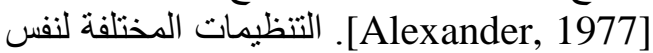

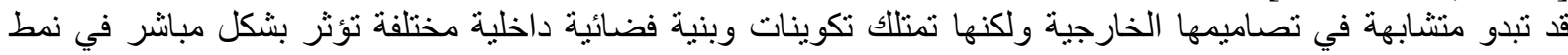

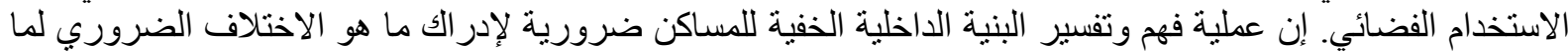
هو عام لأكثرية المساكن.

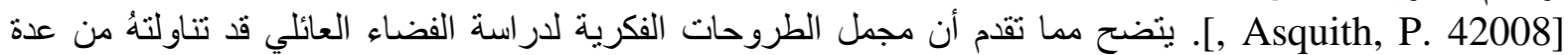

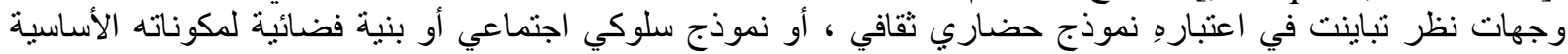

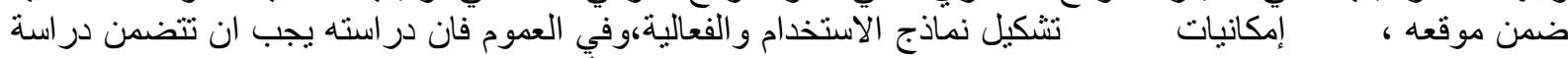

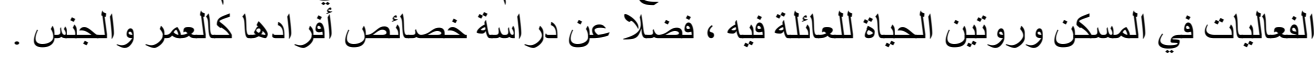

"Evaluating and Illustrating Domestic Space Use", 2008.

2 - 2 - جانب من الاراسات السابقة : 1.2 : Lindsay Asquith 1.2

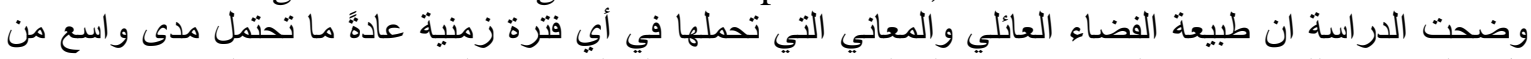

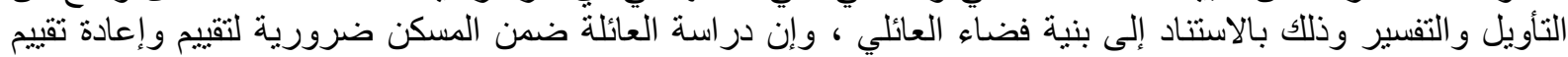

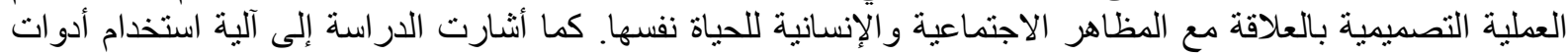
Space Syntax

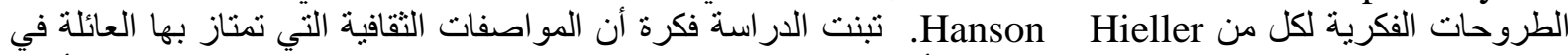

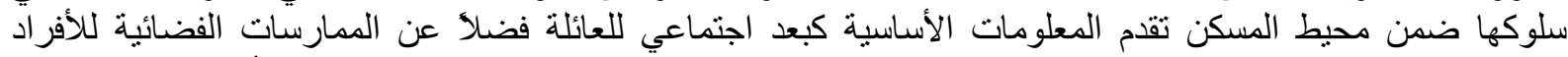

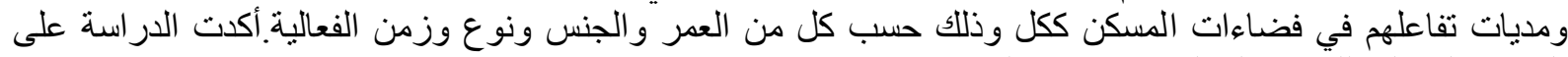

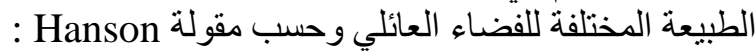

" The important thing about a house is not that it is a list of activities or rooms, but that it is a pattern of space, governed by intricate conventions about what space there are, how they are connected together and sequenced, which activities go together and which are separated out" [Hanson, P2, 1998].

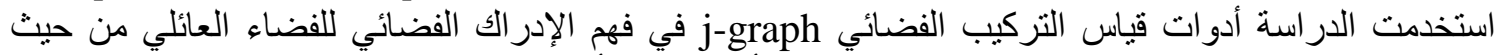

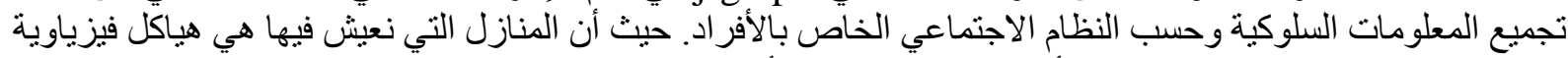

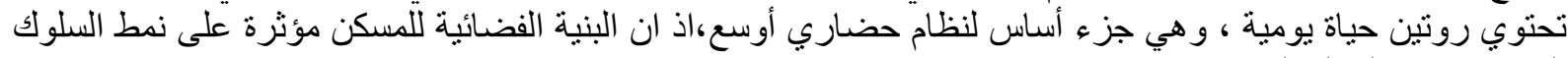

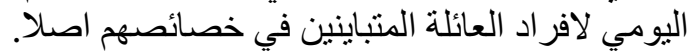


Ching Yang \& Bidc Lapena Jr. 2.2

"A Study on Living Spaces and Daily Interaction and Communication Model of Middle Age Urban Families". 2009

الدراسة على تحليل نماذج أسلوب وروتين الحياة اليومية لنمط من العائلات منوسطة العمر في الفيليبين

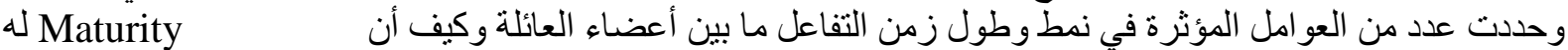

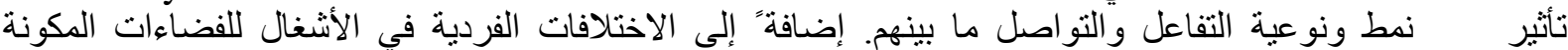

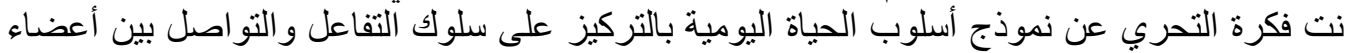

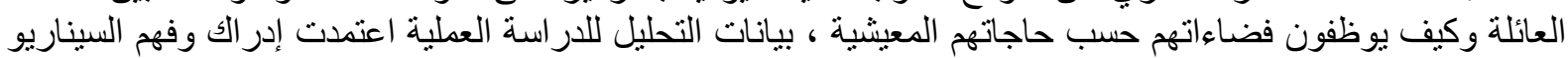

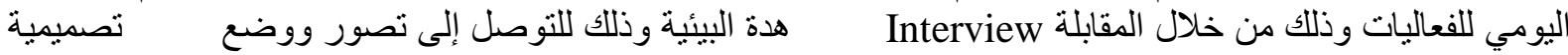
صل و والحاجات الاجتماعية.

Continuity

حددت الدر اسة التعريف الإجر ائي لكل من التفاعلة التفاعل و التو اصل التصل

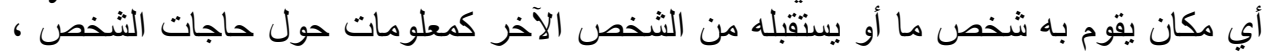

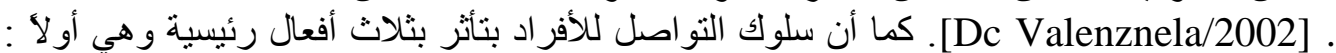

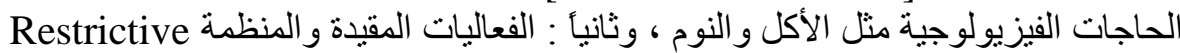

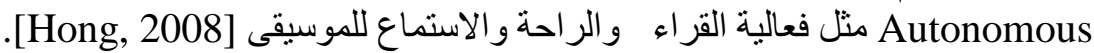

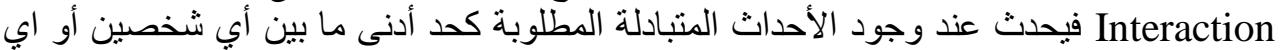

[Sutton/1999]

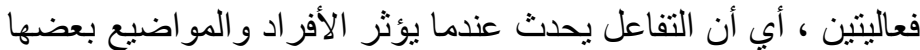

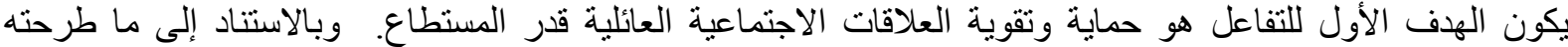

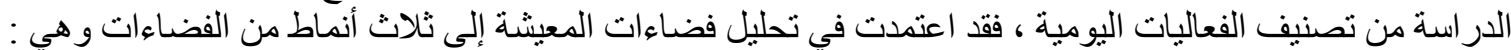

\section{... Private Space}

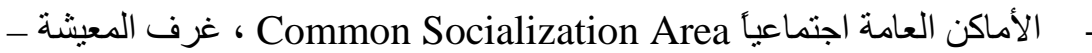

المخصصة لمهمة Task Oriented Space ، المطبخ ، الكر اج ، الغسيل.

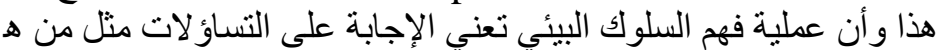

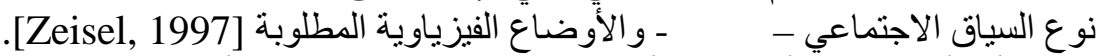

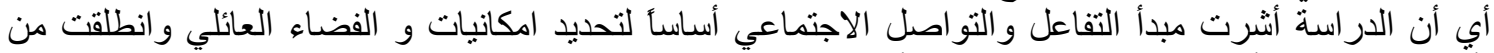

قياسات أنماط الفعاليات و أزما ها في تحديد الفضاء الأكثر إنشغالا وبما يعكس امكانيات الخيار ات التي يوفرهـ للثشاغلين .

"Analyzing Visibility Structures in Turkish Domestic Spaces" 2007

: Guney 3.2

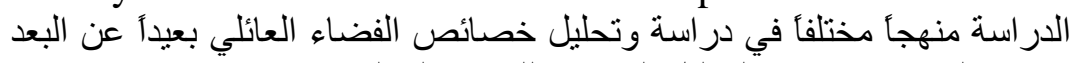

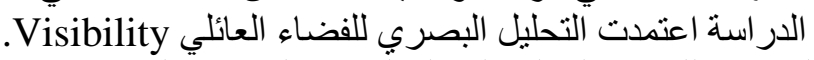

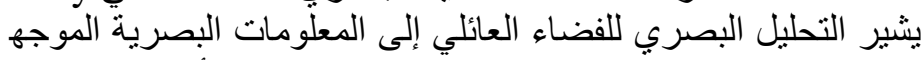

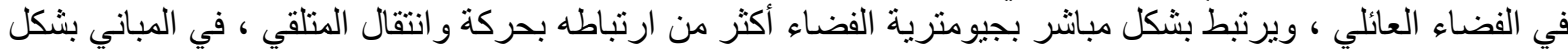

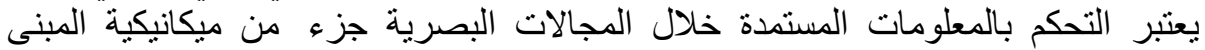

للخصوصية الحيزية Privacy-Territory

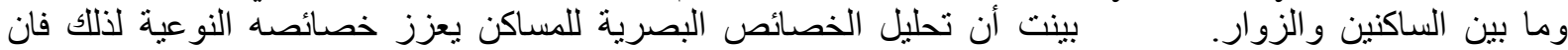

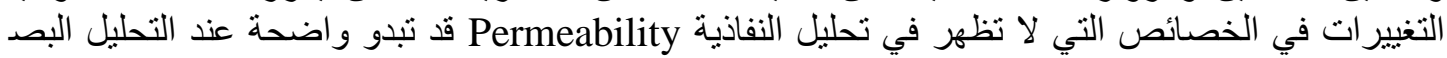

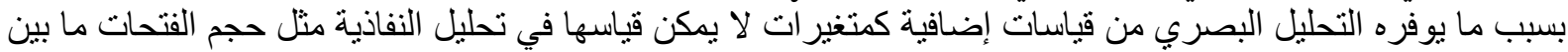

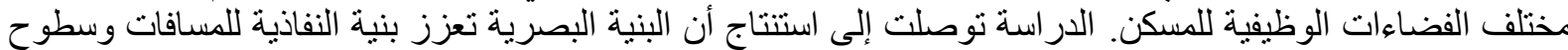

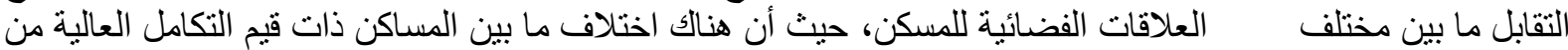

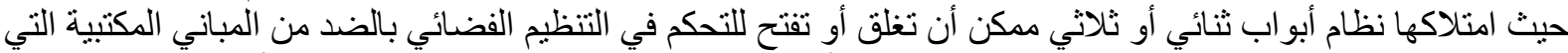

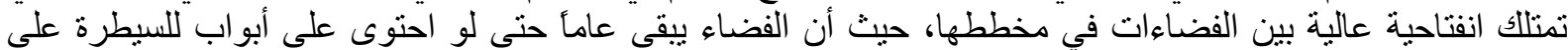

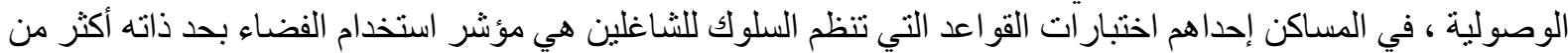

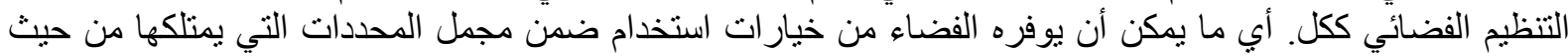
الوصولية و النفاذية البصرية. 
[Guney, P. 38, 2007]. هذا وقد اعتمدت الدراسة تحليل المخطط البصري Isovist في قياس الخصائص الممكنة عينة منتخبة من المساكن في تركيا.

\section{: Capoglu 4.2}

"The Making of Domestic Space at Yesiltepe Blocks-Ankara-Home as a Place"2008

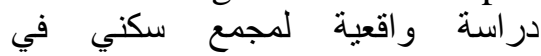

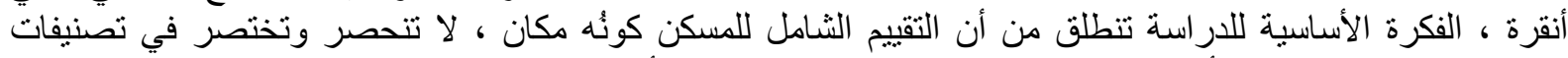

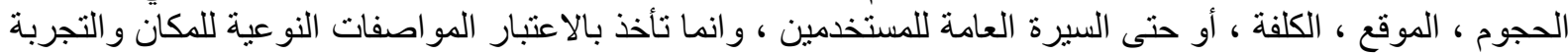

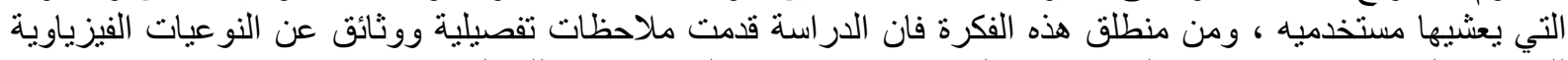

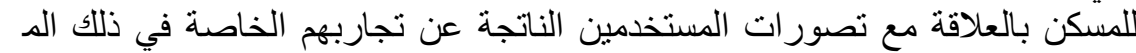

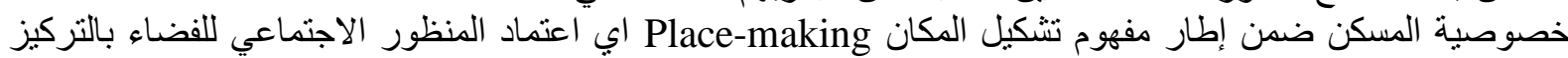

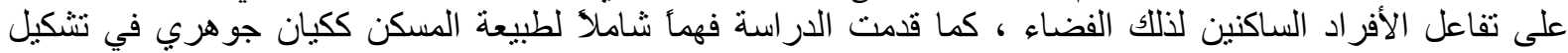

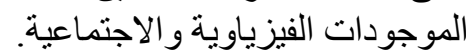

حددت الدر اسة أربعة مظاهر متر ابطة ومنر اكبة للفضاء العائلي و علاقته المتبادلة مع مستخدميه وهي كل من : مesidential Satisfaction

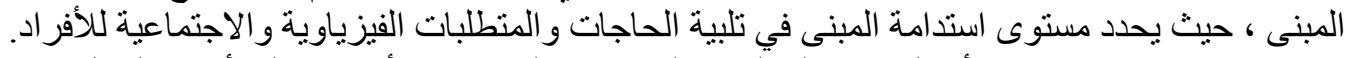

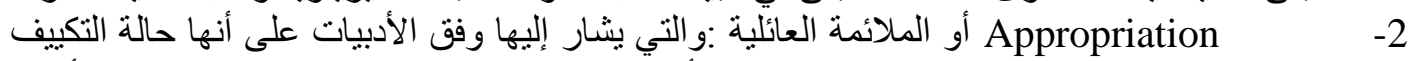
Commodification

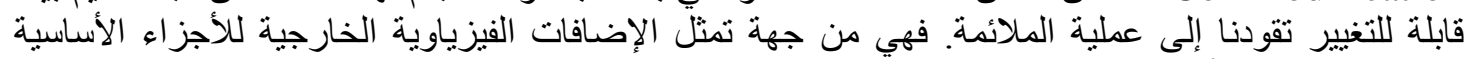

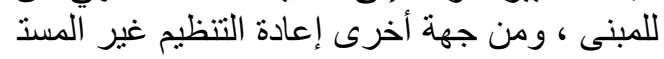
: وتمثل كل الأشياء الخاصة بأفر اد العائلة وقو انينها في للايكور الداخلي.

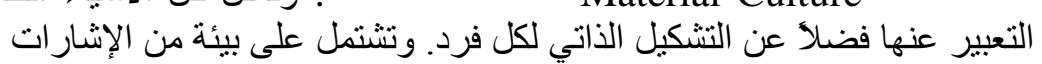

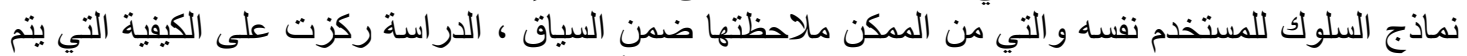

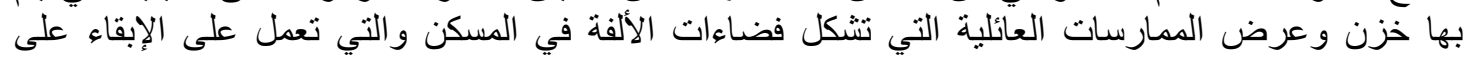
الإحساس بتاريخ العائلة.

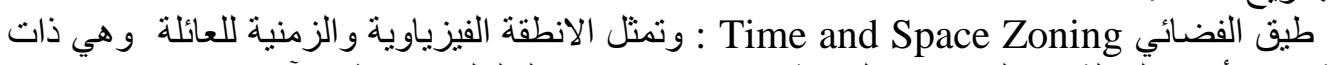
$-1$

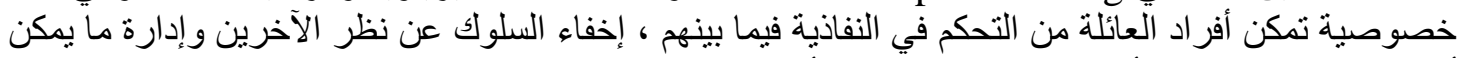

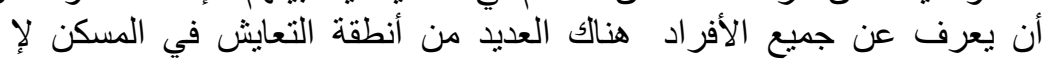

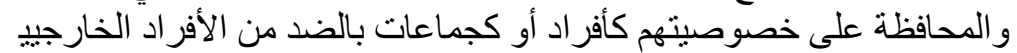

للتوصل إليه وهي كل من : الخيار

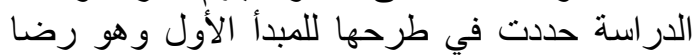

Congruity Flexibility

Choice

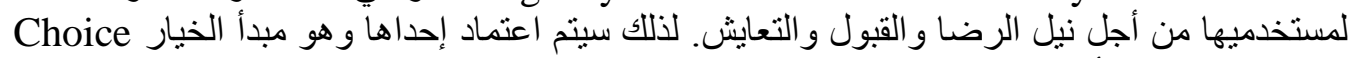

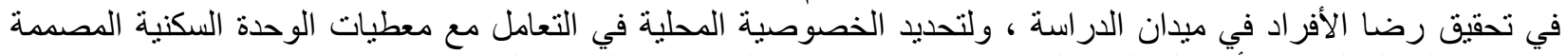
ومستوى البدائل المكنة لأداء الفعاليات اليو مية ضمن الفضاء العائلي كمؤشر لأدرجة الخيار.

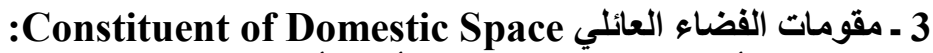

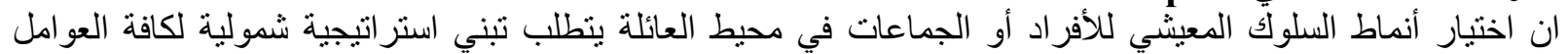

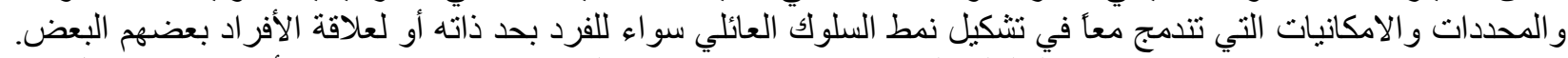

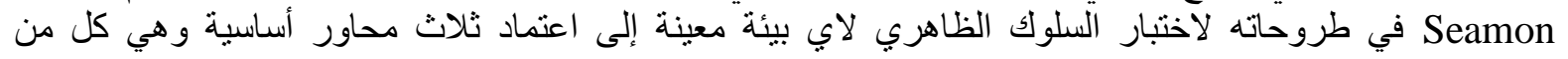

[Seamon, 2007]

1- الفهم الموضو عي لطبيعة الو اقع الفعلي للتجربة الحياتية. [ الفضاء العائلي ]. 2- - طبيعة الأفر اد المندمجين في واقع التجربة التئة الحياتية.

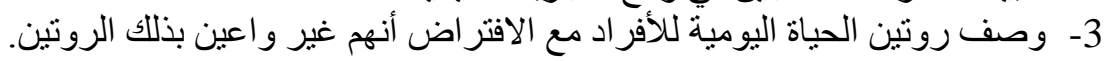


وذللك لتحديد النمط الخاص لبنية المكان الذي يشترك فيه الأفر اد بانتظام فضائي مؤقت ويلتحم ضمنياً مع ديناميكية البيئة الأكبر

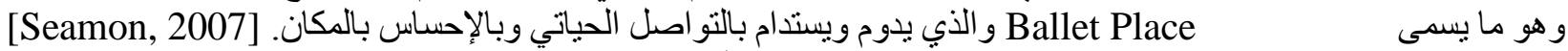
ي لتحديد مظاهر السلوك الحياتي للوحدة الأساسية في المسكن و المتمثلة بالفضاء العائلي ينطلب تحديد

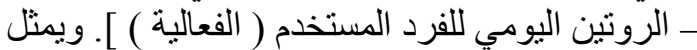

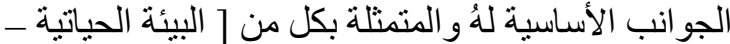
للظاهرة المبحوثة في دراسة لخصوصية الفضاء العائلي المحلي لبيئة

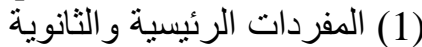

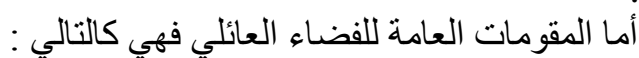

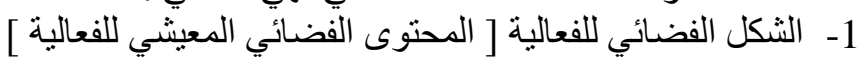

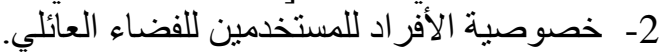 3- نموذج الفعاليات اليومية للفضاء العائلئي. 1.3 - المحتوى الفضائي المعيشي :}

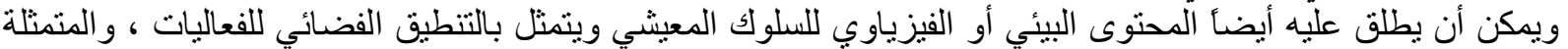

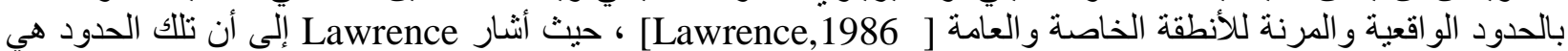

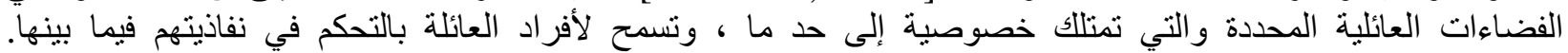

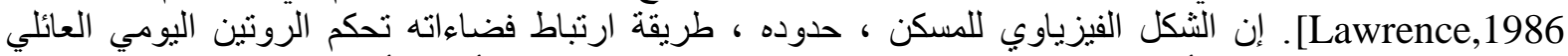

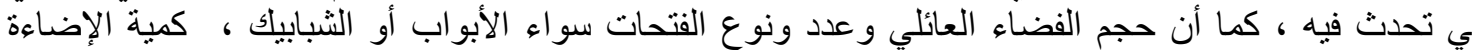

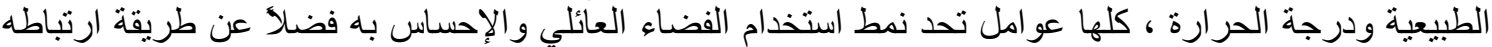

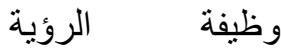
[Asquith, 2007]

السبطرة على الد لومات التي يتلقاها المتلقي أو المستخدم والذي بتضمن الساكنين أنفسهم من جهة و الزوار من جهية

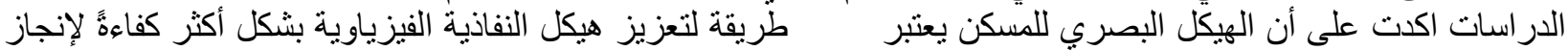

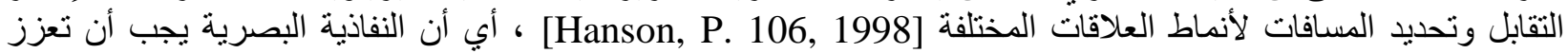

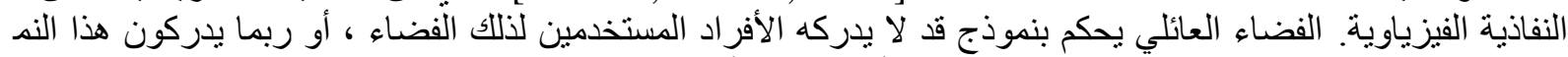

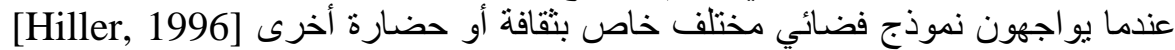
خاص بما يعكس خصوصية ذللك المجتمع. للعينة يحدد طريقة استخدام الفضاءون فئات فئات

\section{3 ـ خصوصية الأفراد المستخدمين للفضاء العائلي:}

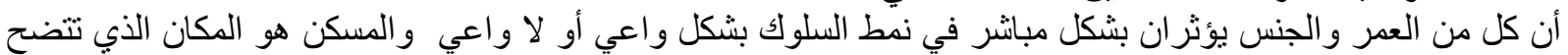

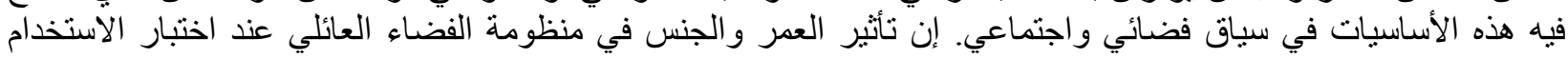
يحدد كسلوك مفترض مستند إلى قيم ومعتقدات ثقافية

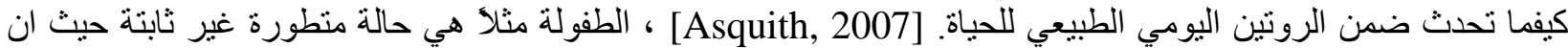

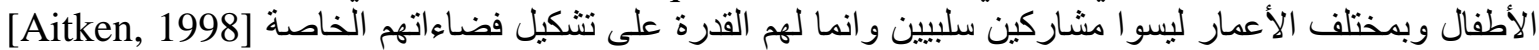

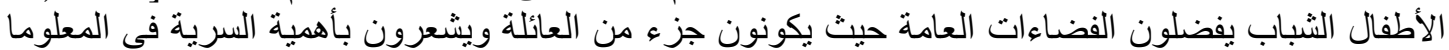
[Asquith, 2007] .

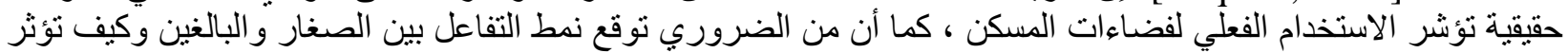

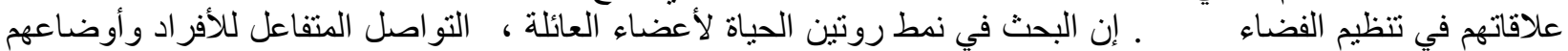

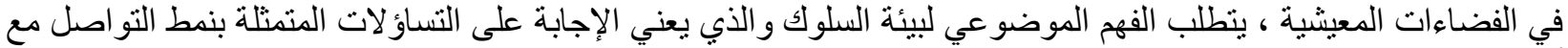

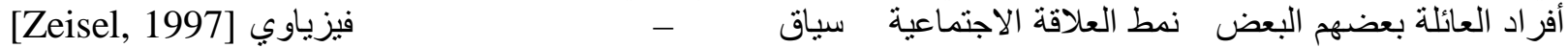

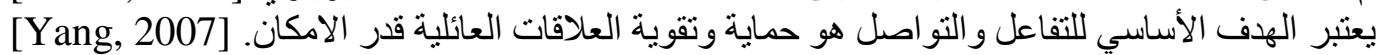
Capoglu

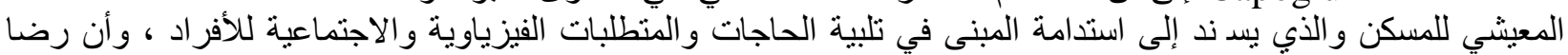

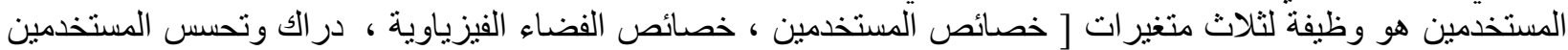

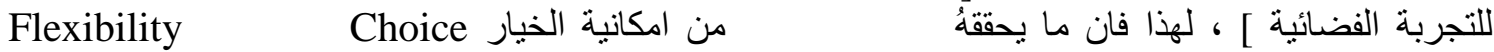
رضن Congruity ، هو ما يحدد مستوى تلبية الفضاء العائلي للحاجات المتعددة و المتنو عة لكافة أعضاء ألعاء العائلة وبالتالي يرفع مسنوى رضائه ]Capoglu, 2008] 


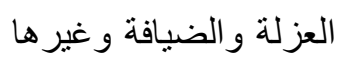

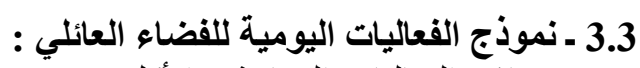

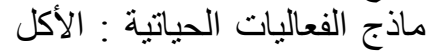

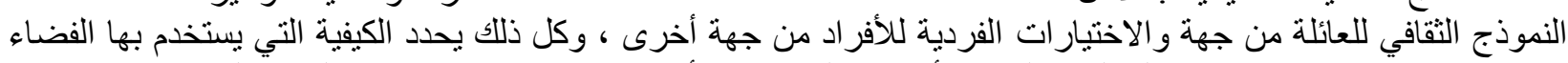

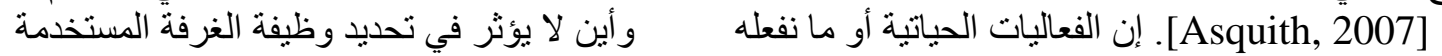

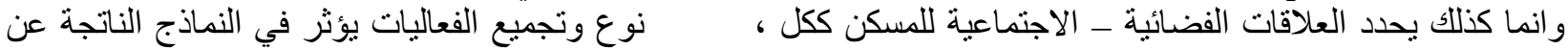

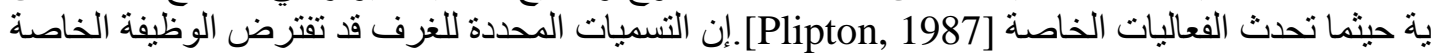

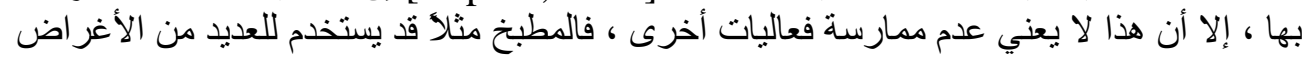

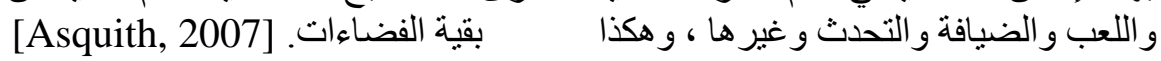
Hong

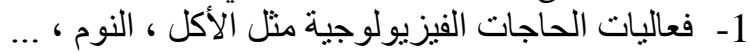

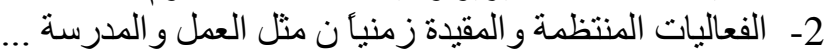

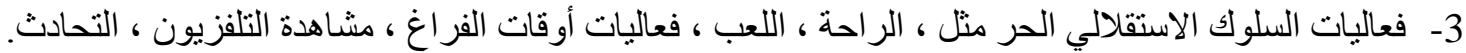

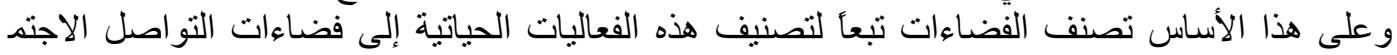

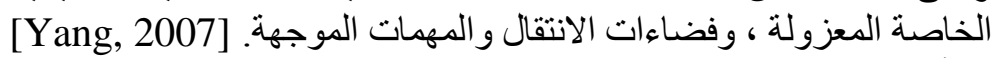

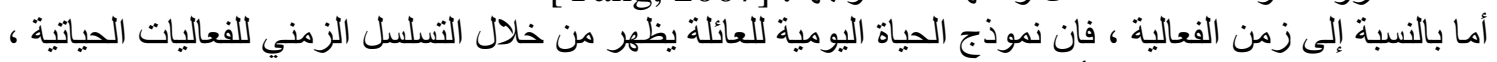

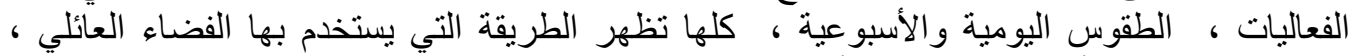

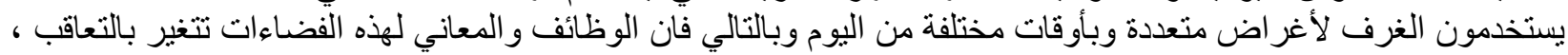
[Asquith, 2007] .

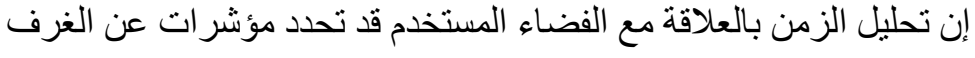

4 ـ منهجية البحث والاراسة العملية :

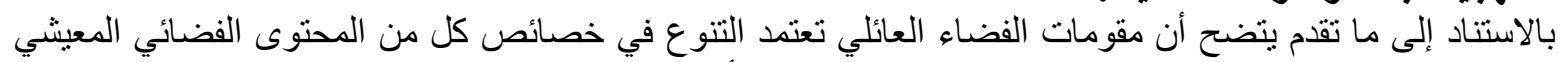

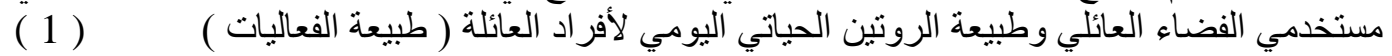

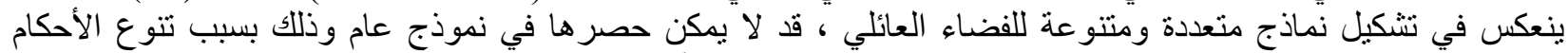

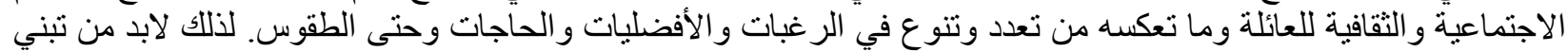

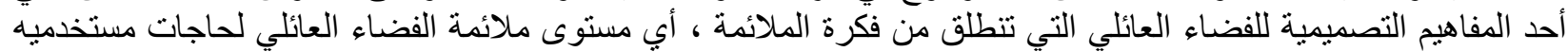

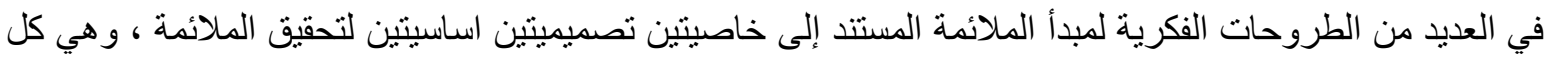

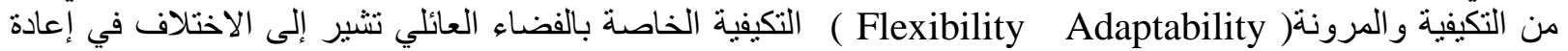

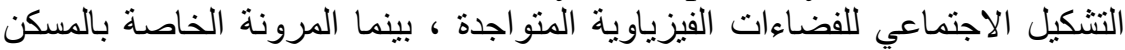

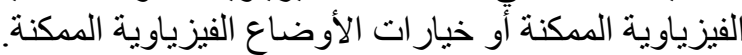

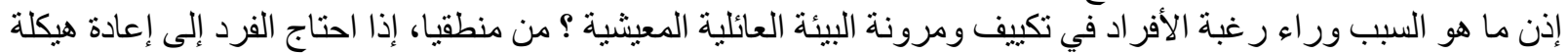

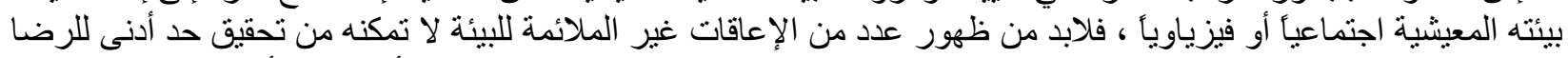

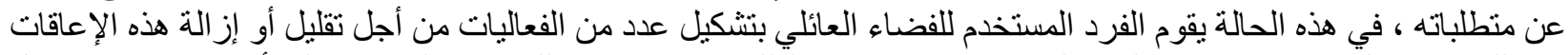

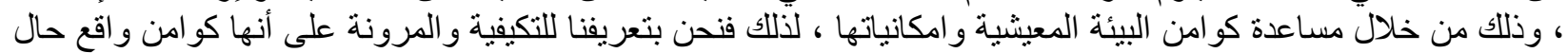

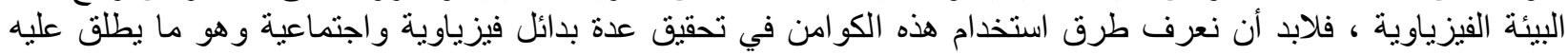
[Capoglu, P. 1314, 2008]

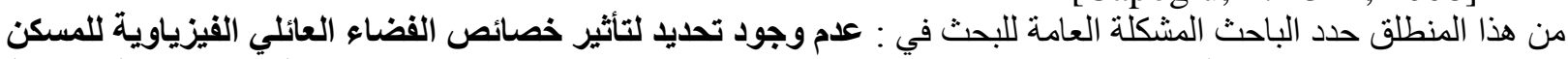

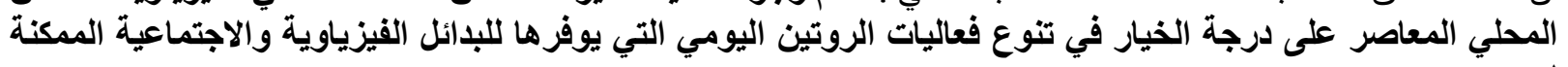
لمستخدميه. فرضية البحثث : تؤثر خصائص الفضاء العائلي الفيزياوية (الجيومترية والبصرية ـ مجال الروئية ) على درجة الخيار في تنوع فعاليات الروتين اليومي التي تثم فيه من قُبل الفراد التئ العائلة. 
جدول (1) : المفردات الرئيسية والثانوية لمقومات الفضاء العائلي ضمن حدود المسكن /المصدر : الباحث

\begin{tabular}{|c|c|c|c|}
\hline شكل الفضـناء & & \multirow{17}{*}{ خصنائص المحيط المعيشي } & \multirow{39}{*}{ العقائلي المعيشيت الفضايه } \\
\hline هوفح الفضـاء & \multirow{8}{*}{ خصائصل الفضذاء } & & \\
\hline جانبي & & & \\
\hline منعزل & & & \\
\hline التنطيق الفضائي للفحاليات الثتواجذة & & & \\
\hline علاقتَه بالتنظبم الفضاثي & & & \\
\hline الثفاذية الفيزيلوية & & & \\
\hline النفاذية البصرية / مجال الروويا & & & \\
\hline بعد ألفضـاء عن الكذخل & & & \\
\hline نمط التاتثبث/ /مرونة الناتثبث & & & \\
\hline المرونة في الاستخدام & & & \\
\hline الخيار وتعدد الببدائلن & & & \\
\hline الملائنة لحاجات المنتخدمين / درجة & & & \\
\hline الاستجنية & خصائص عناصر الفضـاء & & \\
\hline درجة حر ارة الفضناء & & & \\
\hline عدد النو افذ والابواب المحددث للفضشاء & & & \\
\hline Faucal point & & & \\
\hline تتوع في الاعمار & الفظذات العمرية & & \\
\hline نقارب في الاعمار & & & \\
\hline$\varepsilon$ & 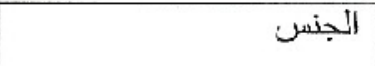 & & \\
\hline ت نقاب & & & \\
\hline أو التحادث & مستوي التواصل الاجتماصي & 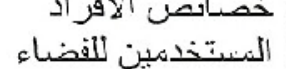 & \\
\hline منتظم & طبيعة الروتين الثبومي & المعيثي & \\
\hline 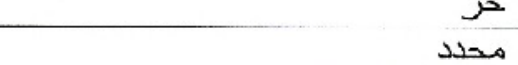 & 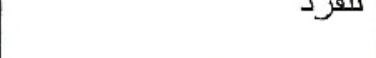 & & \\
\hline & النمط الثقافي لمجتمع العاتلّة & & \\
\hline & مستوبى الزرضـا و القبول & & \\
\hline محذوبد & مستوى الثنكيبة سع & & \\
\hline عالْي & معطبات الفضاء & & \\
\hline موقع الفعالية / الحجم الفضنائي للفعالية & & & \\
\hline طبيعة الفحالية مقيدة & & & \\
\hline حياتية & & & \\
\hline حرة & نسط الفعاليات & & \\
\hline مستوى تتوع الفعالبات & & & \\
\hline مستّوي دمه الفعائبتات & & خصدائص نموذج & \\
\hline التنوع في زمن حدوث الفعالية & & الفيو ميتة & \\
\hline تسلسل الفعالية الزمني & & 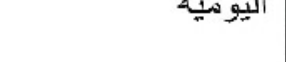 & \\
\hline 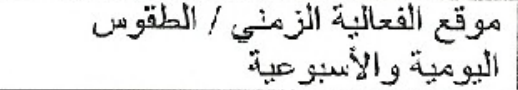 & ز زمن الفعاليات & & \\
\hline تكرار القعالية / منكرر او متفطع & & & \\
\hline |آتداخل الززني للفحاليات & & & \\
\hline
\end{tabular}


لأجلّ اختبار فرضية البحث ثم اختبار المساكن المحلية المعاصرة كحقل لإجر اء التطبيق و اكتشاف خصوصبتها ،

5

الفعاليات

(V9- المتغير ات (لفيات

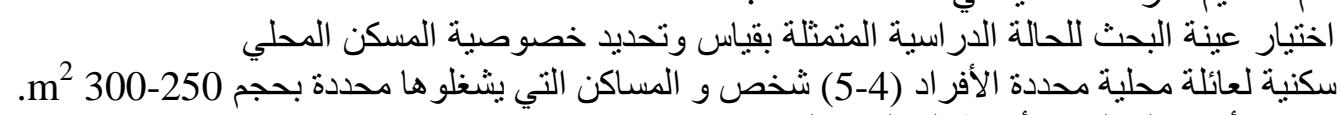

وجدول الروتين اليومي للفعاليات وفق نوالي الأزمنة من الصباح وحتى المساء ليوم عطلة ربيعي . استبانه أفر اد العائلة في أنماط الفعاليات المنتو

قياس درجة الخيار التي يوفر ها الفضاء العائلي بدلالة خاصية التنوع في فعاليات الروتين اليومي التي تحدث من قبل جميع

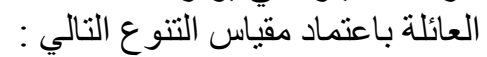

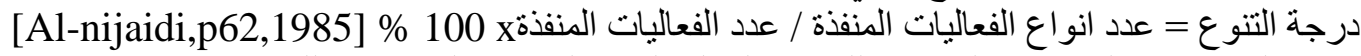

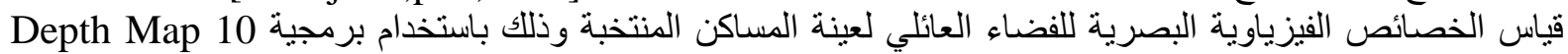

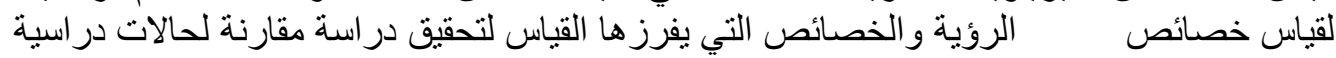

تحليل وتقييم نتائج البحث للتوصل إلى توصيات عامة.

: Isovist Graph 1.5

قياس الخصائص البصرية للفضاء

الملاحظات المدركة من المشاهد المتحرك ، يُعرف مخطط الرؤية Benedik

The set of all points visible from a given vantage point in space and with respect to an environment (Benedikt, 1979, P. 47).

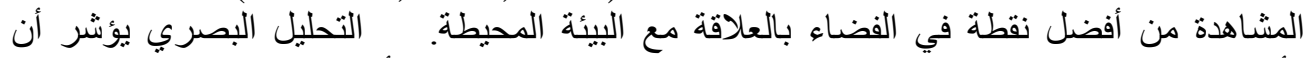

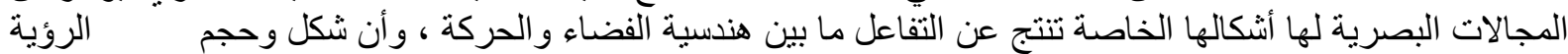

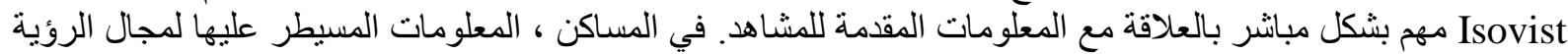

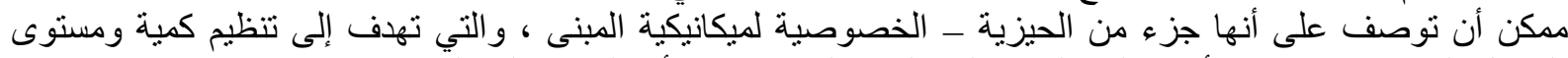

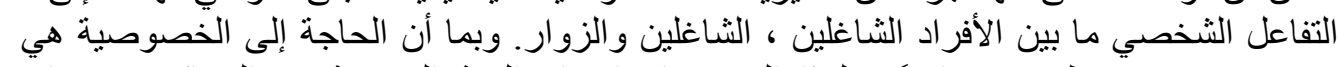

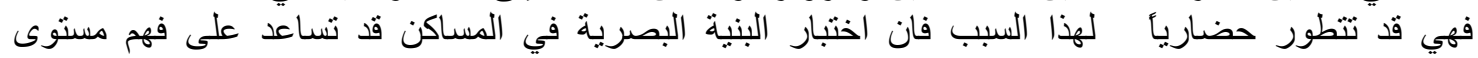

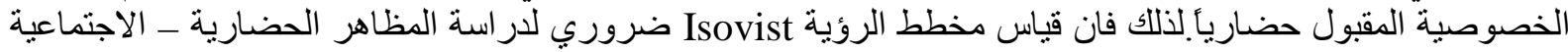

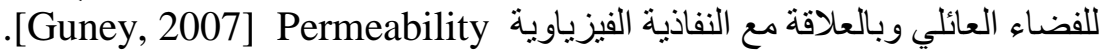

( اعلى قيمة هي اللون الاحمر و اقل

أما البيانات التي يقدمها قياس Isovist Graph فهي كالتالي :

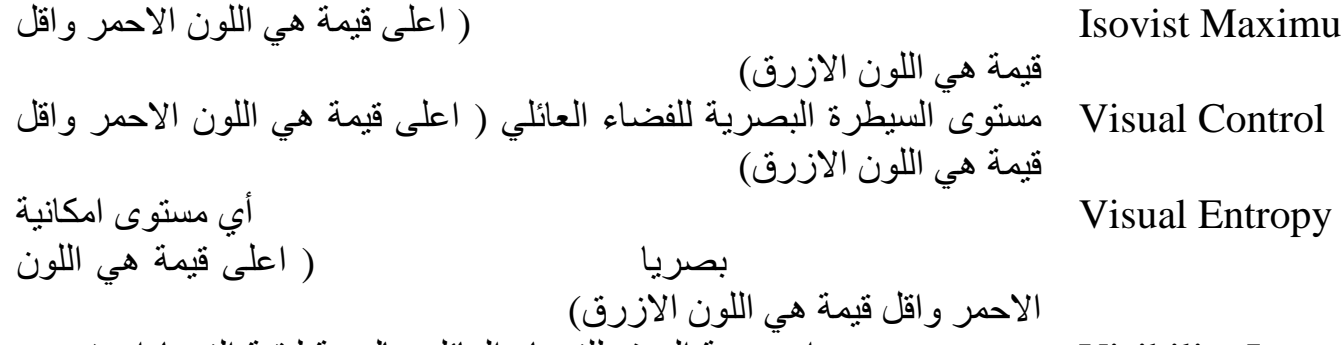

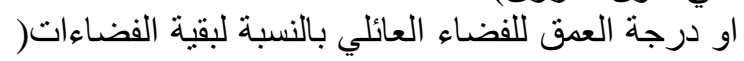

Visibility Integration

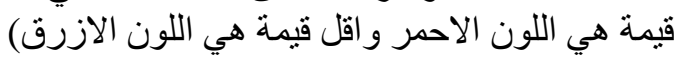

$$
\begin{aligned}
& \text { Isovist Area }
\end{aligned}
$$


6

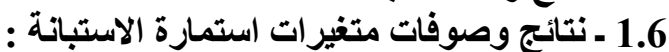

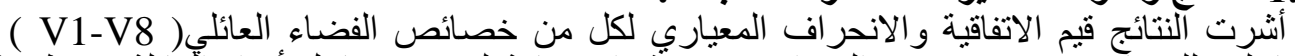

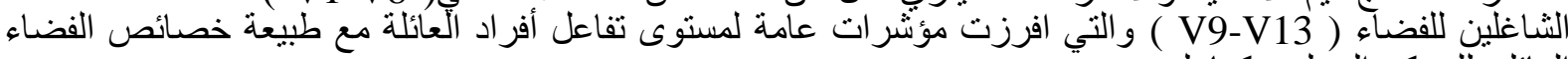

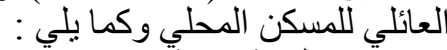

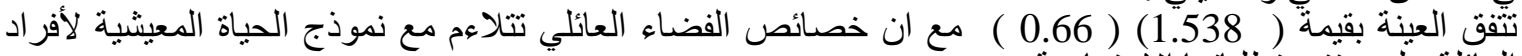

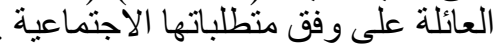

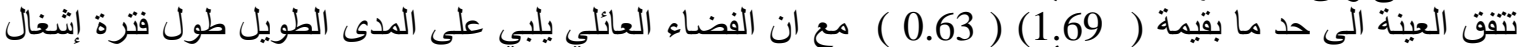
المسكن كافة الاحتياجات الخاصة بأفر الفي اد العائلة.

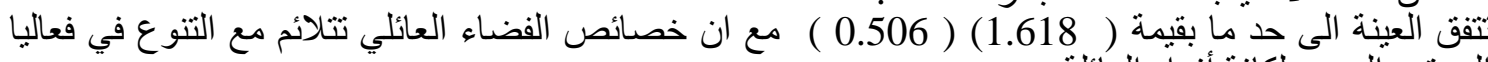
الرونين البومي لكافة أفر اد العائلة

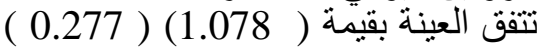

تتفق العينة الى حد ما بقيمة ( 1.798 ( 0.725 ) مع ان الفضاء العائلي يحقق الخصوصية لكافة ممارسة فعالياتهم اليومية مالية تتفق العينة التى حد ما بقيمة ( 1.698 ( 0.63 ) مع انه يمكن لأفر اد العائلة القيام بعدة فعاليات مختلفة ضمن الفضاء تتفق العينة الى حد ما بقيمة ( الجى 1.768) ( 0.83 ) مع ان الفضاء العائلي يمتلك إمكانية التحوير في أسلوب التأثثيث

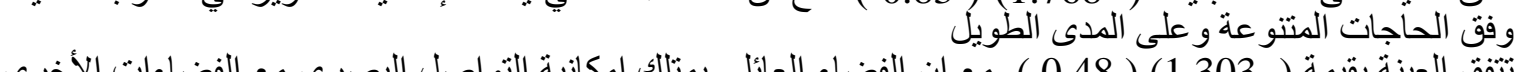

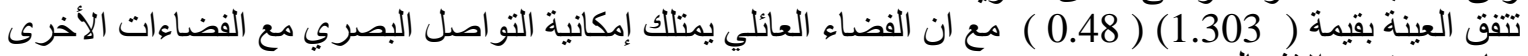

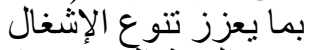

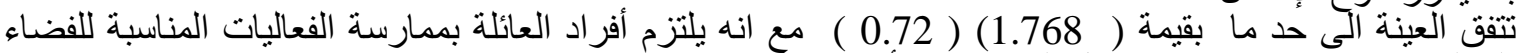

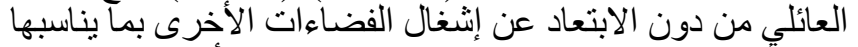
تنفق الّعينة بقيمة ( 1.238) ( 0.43 ) مع الانعان الأفراد يعكسون شخصياتهم المتنو عة عند ممارسة روتين الحياة اليومية تتفق العينة الى حد ما بقيمة ( 1.698 ( 0.75 ) مع مع ان الأفراد يختلفون في مستوى إدراكهم للفعاليات اليومية

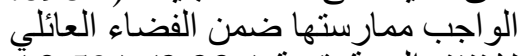

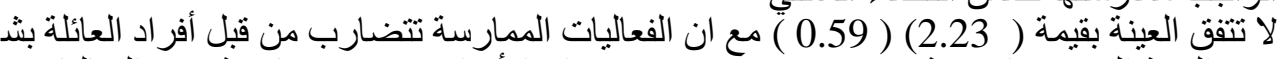

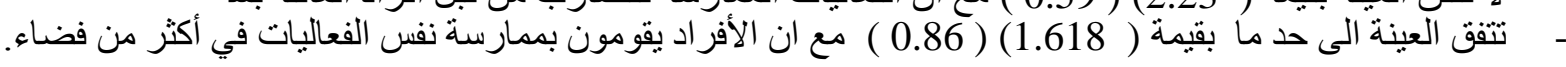

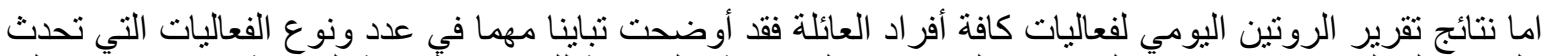

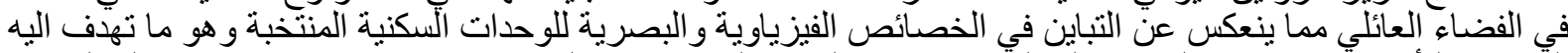

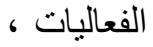

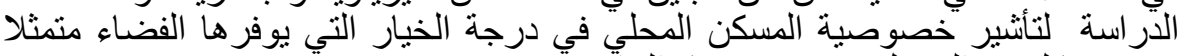

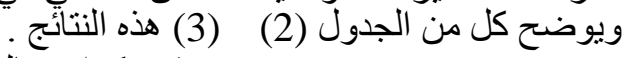
(2) قيم تكر ار فعاليات الروتين اليومي للفضاء العائلي للحالات الدر اسية

\begin{tabular}{|c|c|c|c|c|c|c|c|c|}
\hline \multicolumn{8}{|c|}{ الفعاليات اليومية } & \multirow{2}{*}{ الاراسية } \\
\hline المجموع & العمل & الضيافة & الارس & اللعب & التحدث & الطعام & النوم & \\
\hline 68 & 8 & 8 & 8 & 8 & 16 & 9 & 11 & 1 \\
\hline 46 & 2 & 8 & 4 & 6 & 16 & 0 & 10 & 2 \\
\hline 51 & 3 & 5 & 3 & 8 & 16 & 11 & 5 & 3 \\
\hline 29 & 9 & 2 & 2 & 0 & 7 & 7 & 2 & 4 \\
\hline 44 & 1 & 3 & 9 & 5 & 6 & 12 & 8 & 5 \\
\hline 42 & 8 & 4 & 6 & 6 & 4 & 12 & 2 & 6 \\
\hline 17 & 7 & 0 & 2 & 0 & 4 & 3 & 1 & 7 \\
\hline 21 & 2 & 2 & 8 & 2 & 5 & 1 & 1 & 8 \\
\hline 46 & 5 & 3 & 6 & 4 & 11 & 12 & 5 & 9 \\
\hline 38 & 4 & 2 & 4 & 8 & 5 & 8 & 7 & 10 \\
\hline 36 & 4 & 4 & 8 & 6 & 6 & 8 & 0 & 11 \\
\hline 43 & 2 & 4 & 8 & 4 & 8 & 11 & 6 & 12 \\
\hline 42 & 3 & 4 & 8 & 0 & 13 & 11 & 3 & 13 \\
\hline
\end{tabular}




\begin{tabular}{|c|c|c|c|c|c|}
\hline المعدل & $\begin{array}{l}\text { مساء| } \\
\text { مساء }\end{array}$ & $\begin{array}{l}\text { عصرا } \\
\text { 8-4 }\end{array}$ & $\begin{array}{l}\text { ظهرا } \\
\text { 3-12 }\end{array}$ & صباحا & الحالات الاراسية \\
\hline 41.7 & 36.8 & 46.6 & 38.8 & 46.6 & 1 \\
\hline 37.24 & 37.5 & 31.5 & 40.0 & 40.0 & 2 \\
\hline 47.07 & 36.3 & 53.8 & 43.7 & 54.5 & 3 \\
\hline 51.75 & 57.1 & 57.1 & 50 & 42.8 & 4 \\
\hline 43.3 & 36.3 & 50 & 45.4 & 41.6 & 5 \\
\hline 40.47 & 40.1 & 40.1 & 44.4 & 37.5 & 6 \\
\hline 58.3 & 66.6 & 50 & 66.6 & 50.0 & 7 \\
\hline 65.55 & 50.0 & 66.6 & 75. & 70.4 & 8 \\
\hline 43.66 & 41.6 & 41.6 & 35.7 & 55.5 & 9 \\
\hline 49.7 & 50.0 & 60.1 & 44.4 & 44.4 & 10 \\
\hline 47.9 & 41.6 & 50.0 & 50.0 & 50.0 & 11 \\
\hline 51.11 & 42.8 & 54.5 & 50.0 & 57.1 & 12 \\
\hline 47.47 & 44.4 & 45.5 & 50.0 & 50.0 & 13 \\
\hline
\end{tabular}

(4) قيم الخصائص البصرية للفضاءات العائلية للوحدات السكنبة المنتخبة

\begin{tabular}{|c|c|c|c|c|c|c|}
\hline $\begin{array}{c}\text { Plan } \\
\text { N. }\end{array}$ & & $\begin{array}{c}\text { Isovist } \\
\text { Maximum } \\
\text { Radial } \\
\end{array}$ & $\begin{array}{c}\text { Visual } \\
\text { Control }\end{array}$ & $\begin{array}{c}\text { Visual } \\
\text { Entropy }\end{array}$ & $\begin{array}{c}\text { Visual } \\
\text { integration }\end{array}$ & $\begin{array}{c}\text { Isovist } \\
\text { area }\end{array}$ \\
\hline \multirow{2}{*}{1} & Main hall & 9.01963 & 1.18298 & 1.23423 & 1.29851 & 42.0557 \\
\hline & living & 10.3432 & 1.11797 & 1.5296 & 1.09075 & 40.167 \\
\hline \multirow{2}{*}{2} & Main hall & 11.5514 & 1.38481 & 1.22981 & 9.06403 & 60.0308 \\
\hline & living & 4.88051 & 0.885437 & 1.67006 & 4.25836 & 25.1384 \\
\hline 3 & Main hall & 8.43517 & 1.35557 & 1.01511 & 12.7446 & 48.8478 \\
\hline 4 & Living & 9.10456 & 0.806996 & 1.47696 & 5.89857 & 28.9524 \\
\hline 5 & Main hall & 9.34531 & 1.61538 & 0.999949 & 10.6198 & 41.1473 \\
\hline \multirow{2}{*}{6} & Atrium & 10.6788 & 1.34873 & 1.5654 & 7.10219 & 61.533 \\
\hline & Living & 8.53187 & 0.849302 & 1.70156 & 4.62718 & 37.5264 \\
\hline \multirow{2}{*}{7} & Main hall & 8.76425 & 1.26756 & 1.22171 & 8.14361 & 46.1803 \\
\hline & Living & 7.87164 & 1.1538 & 1.59648 & 7.16159 & 49.3106 \\
\hline 8 & Living & 9.76122 & 1.08824 & 1.63836 & 6.44762 & 47.4974 \\
\hline 9 & Main hall & 8.60798 & 1.29038 & 0.935768 & 8.66852 & 37.4092 \\
\hline 10 & Main hall & 8.84915 & 1.1083 & 1.16028 & 7.85201 & 35.6161 \\
\hline 11 & Main hall & 9.99075 & 1.29118 & 1.32883 & 8.34142 & 43.2468 \\
\hline 12 & Main hall & 9.18381 & 1.23605 & 1.31943 & 9.06849 & 51.5518 \\
\hline \multirow{2}{*}{13} & Main hall & 10.6944 & 1.43871 & 0.984145 & 10.8744 & 67.519 \\
\hline & Living & 13.0347 & 1.28234 & 1.26048 & 10.1972 & 68.3942 \\
\hline Mean & & 9.7174 & 1.2507 & 1.2605 & 8.1113 & 47.1125 \\
\hline
\end{tabular}

Depth Map المصدر : برمجية 
2.6 - نتائج الخصائص البصرية للفضاء العائلي للحالات الاراسية :

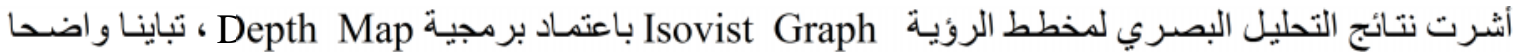

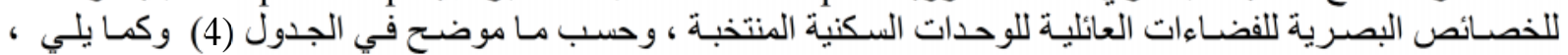

الرؤية

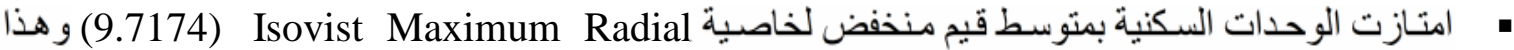

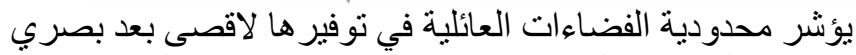

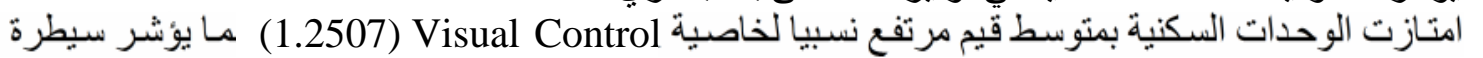

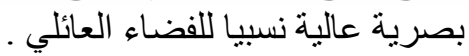

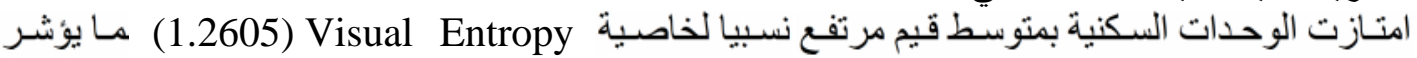

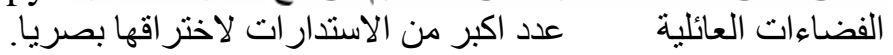

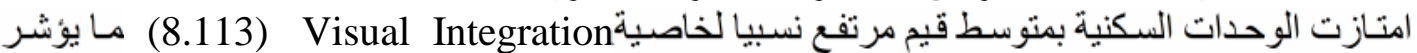

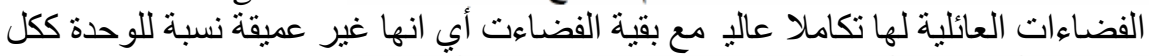

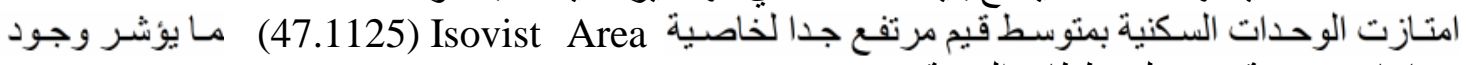

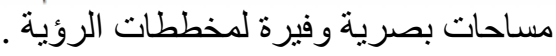

3.6 ـ نتائج التحليل الإحصائي لعلاقات المتغيرات :

يثير الجدول (5) علاقات الارتباط المؤثرة ما بين الخصائص البصرية للفضاء العائلي وخاصية التنوع( كمؤشر لقياس

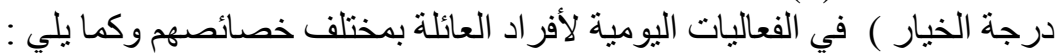

• علاقة ارتباط متوسطة عكسية بقيمة (

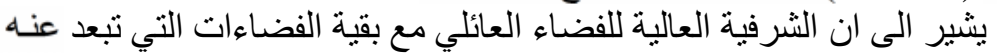

، قد تحد من قيام الأفر اد بعدد اكبر من الفعاليات اليومية ـ ـ ( مخطط مسكن 13 ) ) .

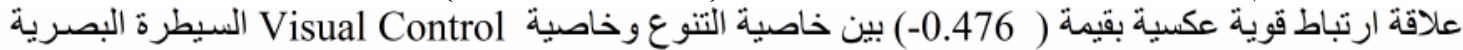

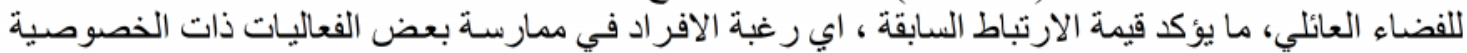

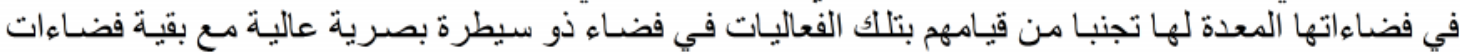

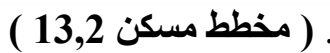

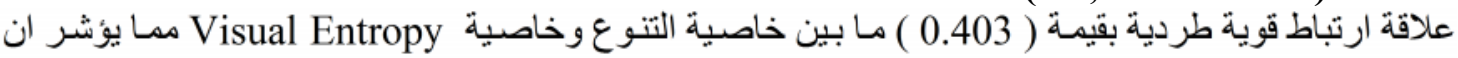

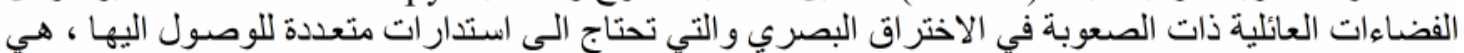

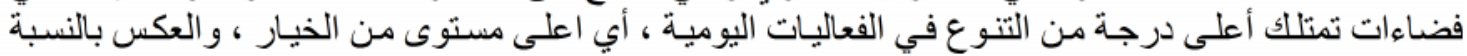

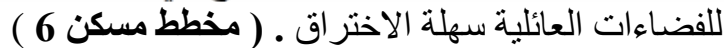

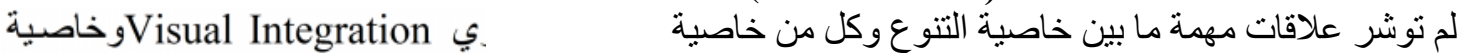
مـايؤشر .ان عمق الفضـاء العـائلي وحجم مخطط الرؤيسة هي عو امل محايدة بالنسبة للظـاهرة

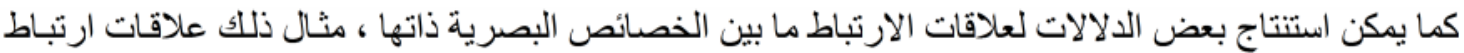

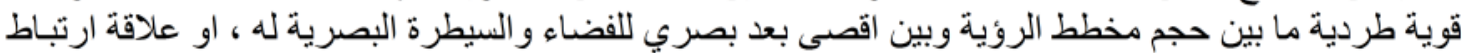
عisual Entropy عكية قوية ما بية ما بين 
(5) قيم علاقات الارتباط لقيم كل من خاصية التنوع و الخصائص البصرية للفضاء

Correlations

\begin{tabular}{|c|c|c|c|c|c|c|c|}
\hline خاصية التتوع & $\begin{array}{c}\text { Isovist } \\
\text { Area } \\
\end{array}$ & $\begin{array}{c}\text { Visual } \\
\text { Integration }\end{array}$ & $\begin{array}{l}\text { Visual } \\
\text { Entropy }\end{array}$ & $\begin{array}{l}\text { Visual } \\
\text { control }\end{array}$ & $\begin{array}{c}\text { Isovist } \\
\text { Maximu } \\
\text { m Radial }\end{array}$ & & \\
\hline-.343 & $.724(* *)$ & .060 & .275 & .306 & 1 & $\begin{array}{c}\text { Pearson } \\
\text { Correlation }\end{array}$ & $\begin{array}{c}\text { Isovist Maximum } \\
\text { Radial }\end{array}$ \\
\hline .086 & .000 & .771 & .174 & .129 & . & Sig. (2-tailed) & \\
\hline$-.476(*)$ & $.558(* *)$ & $.570(* *)$ & $-.563(* *)$ & 1 & .306 & Pearson Correlation & Visual control \\
\hline .014 & .003 & .002 & .003 & . & .129 & Sig. (2-tailed) & \\
\hline $.403(*)$ & .005 & $-.518(* *)$ & 1 & $-.563(* *)$ & .275 & Pearson Correlation & Visual Entropy \\
\hline .041 & .980 & .007 & . & .003 & .174 & Sig. (2-tailed) & \\
\hline-.057 & .334 & 1 & $-.518(* *)$ & $.570(* *)$ & .060 & Pearson Correlation & Visual Integration \\
\hline .783 & .096 & $\cdot$ & .007 & .002 & .771 & Sig. (2-tailed) & \\
\hline-.234 & 1 & .334 & .005 & $.558(* *)$ & $.724(* *)$ & Pearson Correlation & Isovist Area \\
\hline .251 & . & .096 & .980 & .003 & .000 & Sig. (2-tailed) & \\
\hline 1 & -.234 & -.057 & $.403(*)$ & $-.476(*)$ & -.343 & Pearson Correlation & خاصية التنوع في الفعالية \\
\hline & .251 & .783 & .041 & .014 & .086 & Sig. (2-tailed) & \\
\hline
\end{tabular}

** Correlation is significant at the 0.01 level (2-tailed).

* Correlation is significant at the 0.05 level (2-tailed).

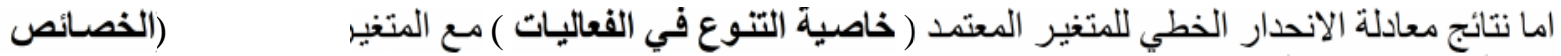
Coefficients(a) : البصرية لمخطط الروية للفضاء التعائلي)

\begin{tabular}{|r|r|r|r|r|l|l|}
\hline \multicolumn{1}{|c|}{ Sig. } & $\mathrm{t}$ & \multicolumn{1}{c|}{$\begin{array}{c}\text { Standardized } \\
\text { Coefficients }\end{array}$} & \multicolumn{2}{|c|}{$\begin{array}{c}\text { Unstandardized } \\
\text { Coefficients }\end{array}$} & & Model \\
\hline & & Beta & Std. Error & \multicolumn{1}{c|}{$\mathrm{B}$} & & \\
\hline .001 & 3.693 & & 18.890 & 69.765 & (Constant) & 1 \\
.021 & -2.515 & -.625 & 2.000 & -5.030 & Isovist Maximum Radial & \\
.242 & -1.205 & -.317 & 10.268 & -12.372 & Visual control & \\
.022 & 2.475 & .591 & 8.077 & 19.988 & Visual Entropy & \\
.075 & 1.877 & .379 & .552 & 1.037 & Visual Integration & \\
.335 & .988 & .267 & .187 & .185 & Isovist Area & \\
\hline
\end{tabular}

a Dependent Variable: خاصية التنوع في الفعالية SPSS المصدر :برمجية

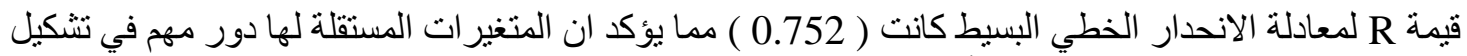

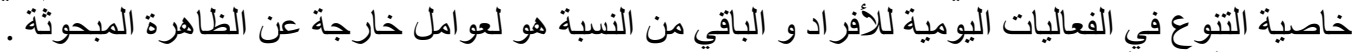

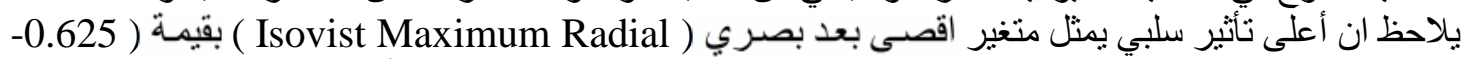

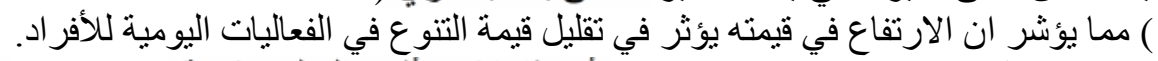

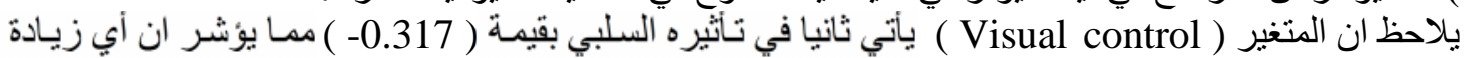

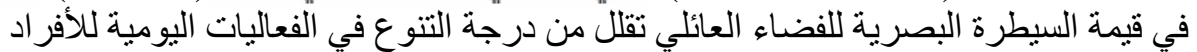

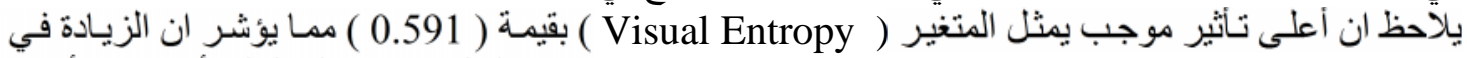

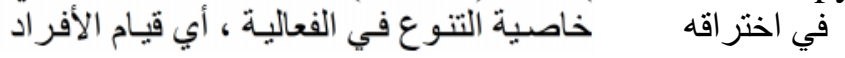
Visual Entropy بعدد اكبر من الفعاليات اليومية ضمنهـ.

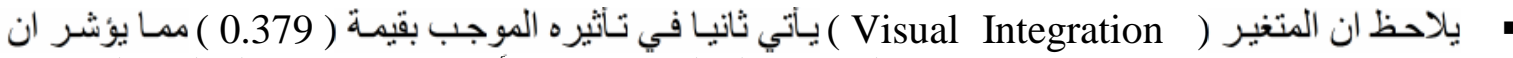

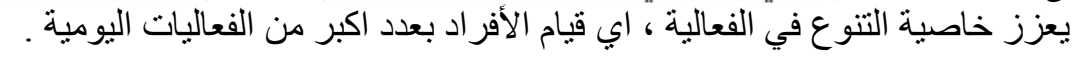


" أظهرت نتـائج وصـوفات متغير ات الاسـتبانة، "الاتفاقيـة العاليـة" ارتباطهـا بالجوانب الاجتماعيـة لنمـوذج الحيـاة

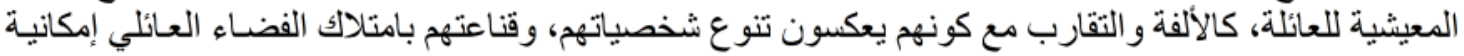
التو اصل، وهذا بدل على اهمية هذا الفضاء في تعزيز الجانب الاجتماعي بين افراد العائلة، من ناحية اخرى إنى فـان

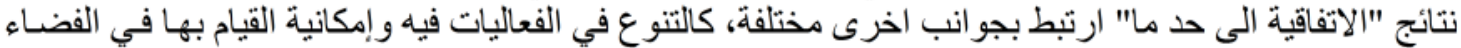

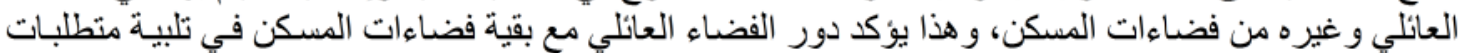

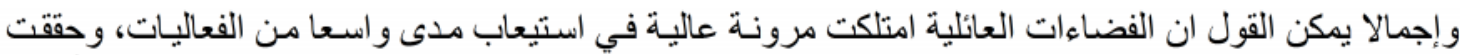

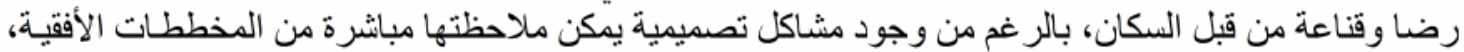

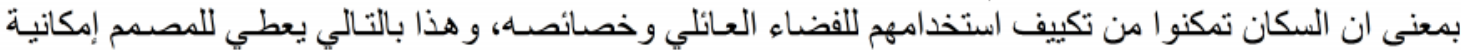

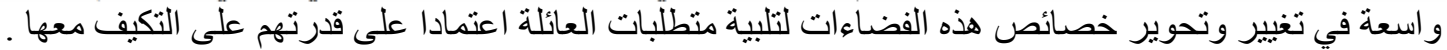

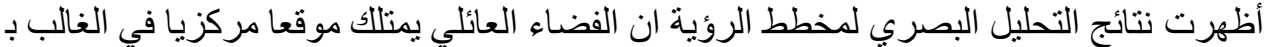

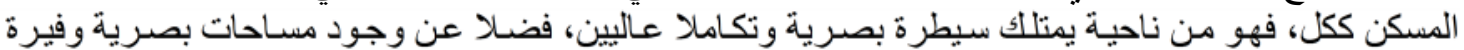

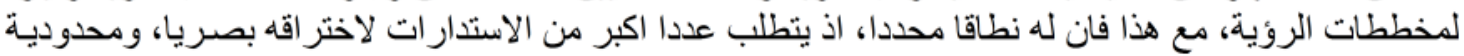

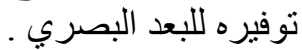

ان نتائج التحليل الإحصائي لعلاقة المتغير ات التي تضمنت العلاقة العكسية القويـة بين ( درجـة الخيـار و السيطرة

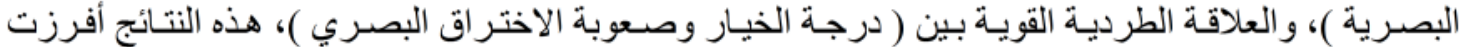

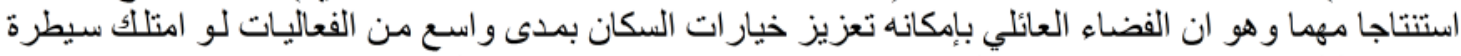

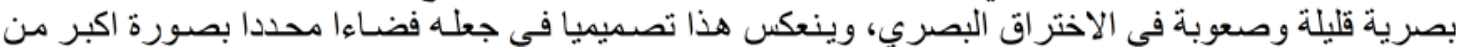

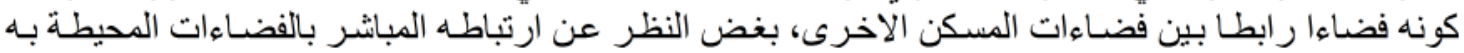

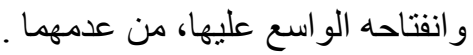

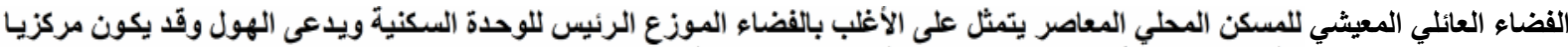

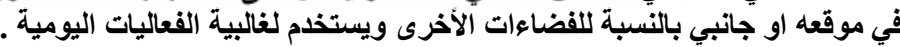

1. Aitken , S., (1998) " Family Fantasies Community space" Rutgers university Press. New Jersey.

2. Alexander, C. Ishikawa, S. Silverstein M.(1977),'A pattern language "Oxford university Press. Oxford, New York.

3. Al-Nigaidi, Hazim,(1985) "Flexibility in the Design of Building " PH.D Thesis .Oxford Polytechnic Oxford .

4. Asquith,. Lindsay, (2008) " Evaluating and Illustrating Domestic Space Use: Collecting and Analysing Behavioral Data for Space" Syntax Analysis" University of Sydney, Sydney, Australia, lindsay@squith.com

5. Asquith, L. Space Use and Claim (2003). An Evaluation of the Domestic Spatial Arrangement in Family Homes. Unpublished PhD Thesis, Oxford Brookes University.

6. Benedikt, M.,(1979) " To Take Hold of Space :Isovists and Isovist Fields " Environment and Planning and Design , 6:47-65.

7. Birdwell-Pheasant, D., Lawrence-Zuniga, D. (1999) "Introduction: Houses and Families in Europe" in Donna Birdwell-Pheasant and Denise ,Lawrence-Zuniga (eds.) House Life: Space, Place and Family in Europe. Oxford, UK.;New York,USA: Berg, 1-35.

8. Capoglu .Nazan,(2008) " Home As A Place :The Making of Domestic Space At Yesiltepe Blocks , Ankara . Thesis submitted to the graduate school of natural and applied science of middle east technical university. Turky

9. Guney, Yasemin ince, (2007) " Analyzing Visibility Structures in Turkish Domestic Space" Proceeding, $6^{\text {th }}$ International space syntax symposium , Istanbul 2007 . 
10. Dealenzuela,J.S.,(2002),Communication,http://www.unm.edu/ devalenz/handouts/defcomm.html

11. Hanson, J. (1998). Decoding Homes and Houses. Cambridge University Press, Cambridge

12. Hong Yi, H., (2008), Modern Nuclear Family Members Interaction and Communication, National Yunlin University, Taiwan

13. Lawrence, R. (1986). Redefining Cultural and Historical Studies of Built Environments in D.Saile (Ed.): Essays in Culture and Built Form, University of Kansas Press, Kansas.

14. Lawrence, R. (1989). Translating Anthropological Concepts into Architectural Practices in S.Low, E. Chambers (Eds.): Housing, Culture and Design: A Comparative Perspective .University of Pennsylvania Press, Pennsylvania.

15. Lawrence, R.J. (1987) “What Makes a House a Home?" Environment and Behavior" 19(2): 154168.

16. Plimpton, C.L, Hassan, F.A. (1987). Social Space a Determination of House Architecture Environment and Planning B: Planning and Design (14) 439-449.

17. Rapaport , A (1978)." Culture and Built Form: A Reconsideration in D. Saile (Ed): Essays in culture and built form . university of Kansas Press. Kansas.

18. Schildkrout, E. (1978). Age and Gender in Hausa Society: Socio-economic Roles of Children in Urban Kano in J.S. La Fontaine (Ed.): Sex and Age as Principles of Social Differentiation. Academic Press, London.

19. Seamon . David ,(2007)," A Lived Hermetic of people and place :Phenomenology and space syntax " . procceding , $6^{\text {th }}$ International space syntax symposium, Istanbul .

20. Sutton,L.,(1999),Interaction,ArizonaStateUniversity,http://seamonkey.ed.asu.edu/ mcisaac/emc70 3/leah5.html.

21. Yang, Dr. Ching, Fortunato B. de la Peña Jr. (2009) "A Study on Living Spaces and the Daily Interaction and Communication Model of Middle Aged Urban Families in the Philippines".

22. Zeisel, J., (1997), Inquiry by Design: Tools for Environment-Behavior Research, Cambridge University Press, USA 


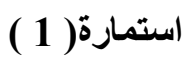

ملحق ( 1 )

بسم الله الرحمن الرحيم

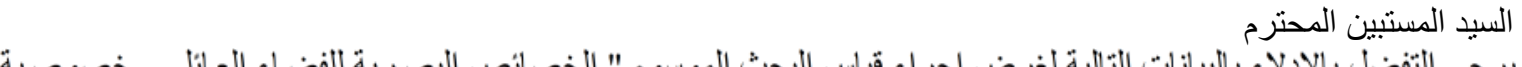

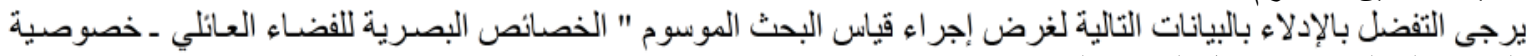
2300 250 200 : حجم الوحدة السكنية

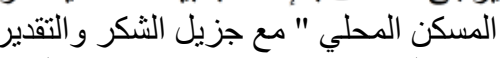

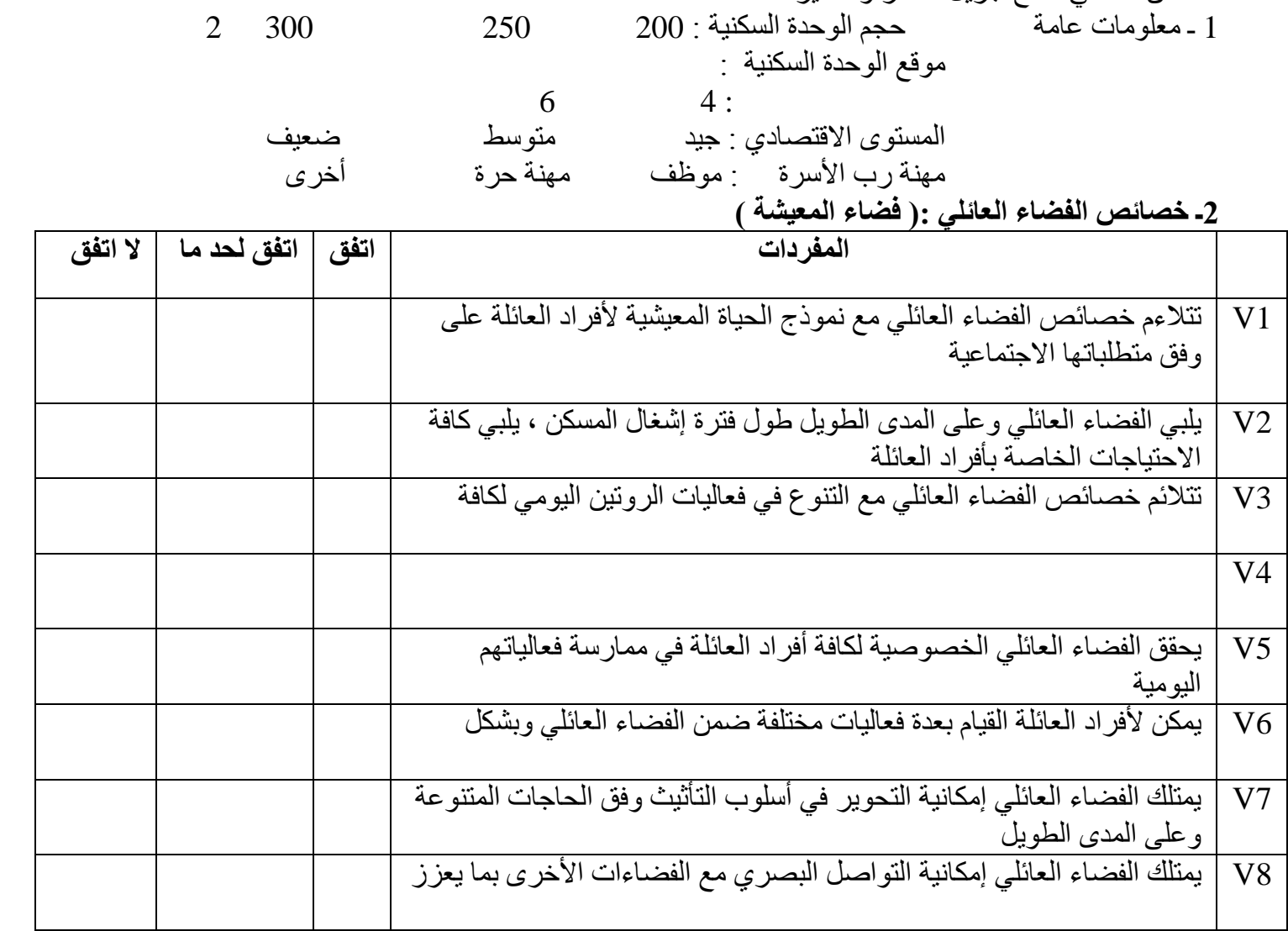

\begin{tabular}{|c|c|c|c|c|}
\hline لا اتفق & 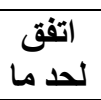 & اتفق & المفردات & \\
\hline & & & 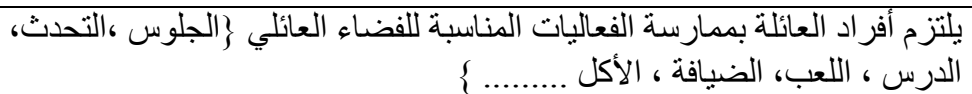 & V9 \\
\hline & & & يقوم أفر اد العائلة بممارسة نفس الفعاليات السابقة بأكثر من فضاء في المسكن & V10 \\
\hline & & & يقوم أفر اد العائلة بفعالياتهم الخاصة بشكل حر ومن دون تدخل الآخرين & V11 \\
\hline & & & تتضارب الفعاليات اليومية الممارسة من قبل أفراد العائلة مع بعضها البعض & V12 \\
\hline & & & يختلف إفر اد العائلة في مستوى إلدر اكهم للفعاليات الممكنة ضمن الفضاء العائلي & V13 \\
\hline
\end{tabular}

4ـ تسجيل الروتين اليومي للفعاليات الحياتية لأفراد العائلة وفق الجدول المرفق

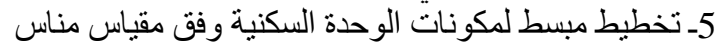


الدباغ: أثر الخصائص البصرية الفيزياوية للفضاء العائلي على درجة الخيار للفعاليات اليومية ـ المسكن المعاصر ---

استمارة رقم ( 2 ) بيانات الفعاليات اليومية للعائلة ليوم 20 اذار 2013

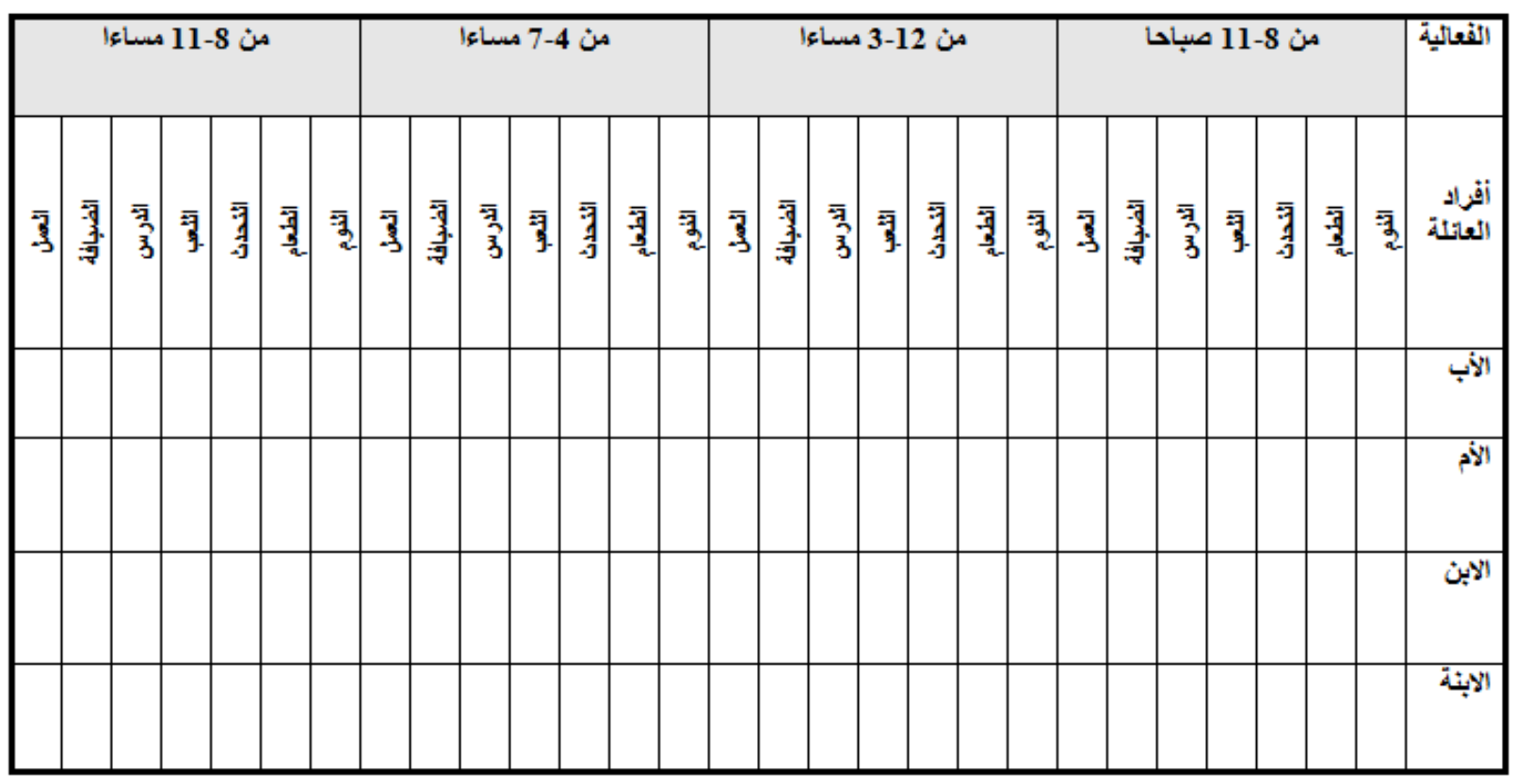

الرؤية Isovist Graph للوحدات السكنية المنتخبة

(2)

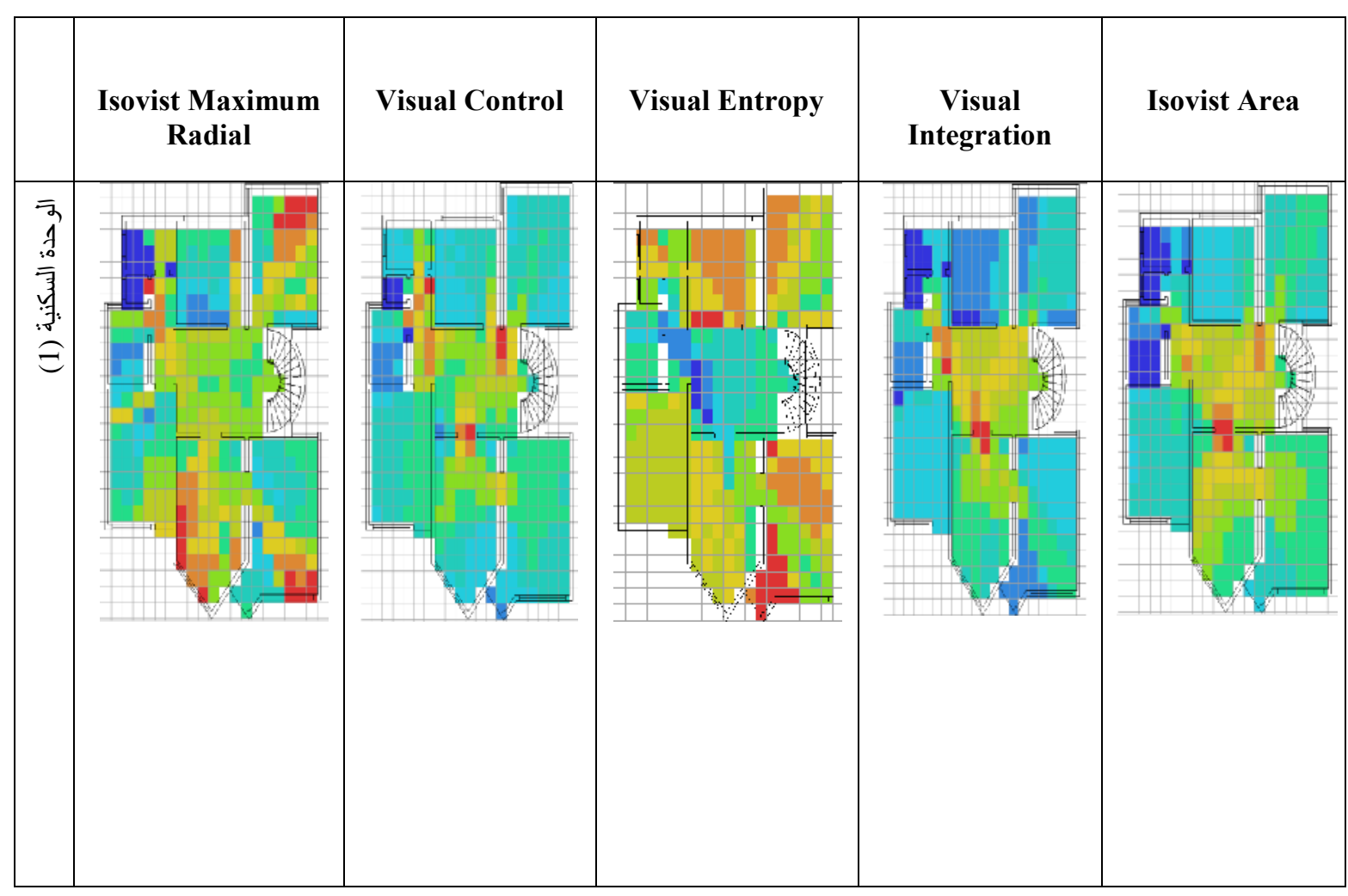


Vol. 23

No. 3

June 2015

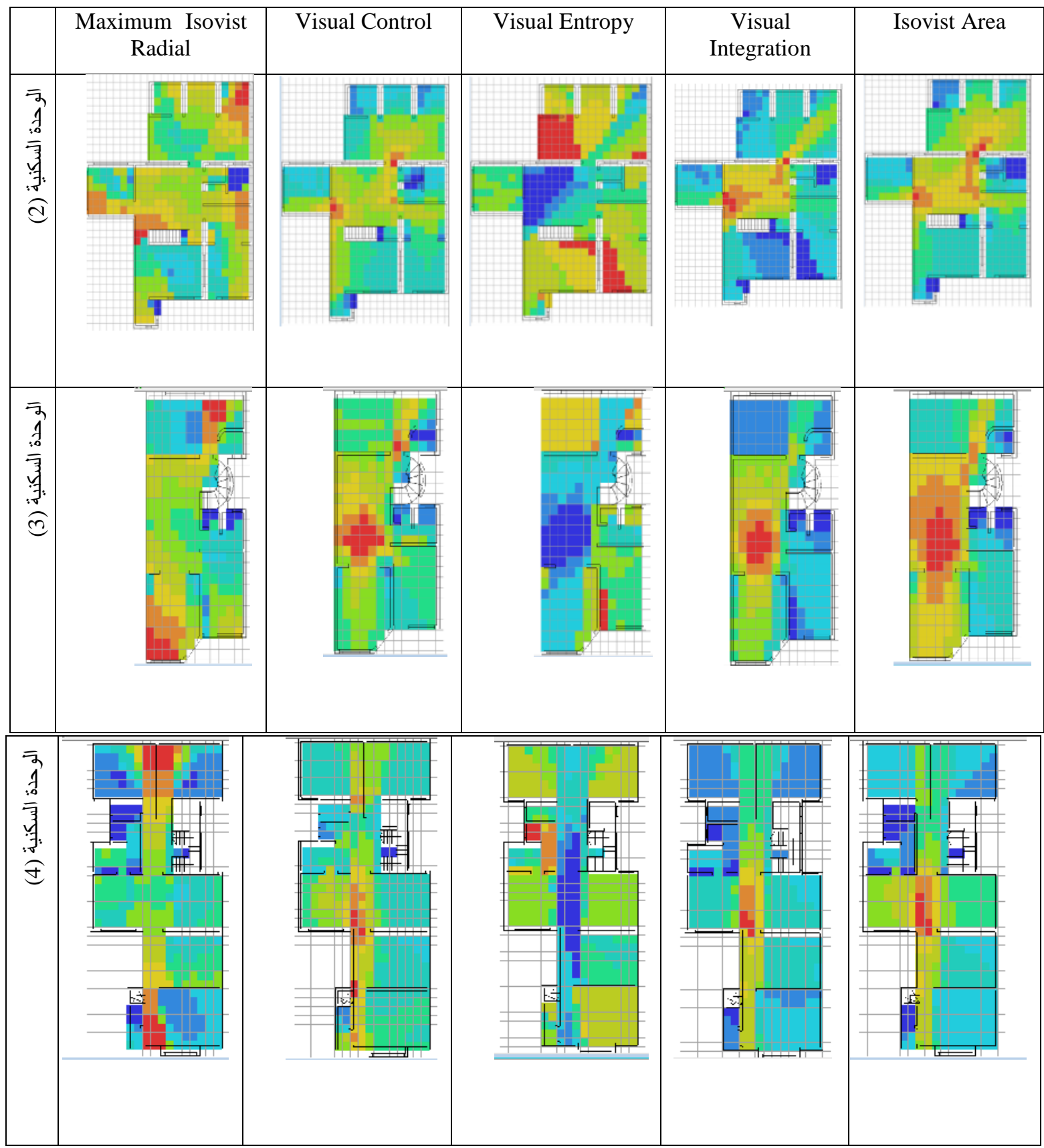




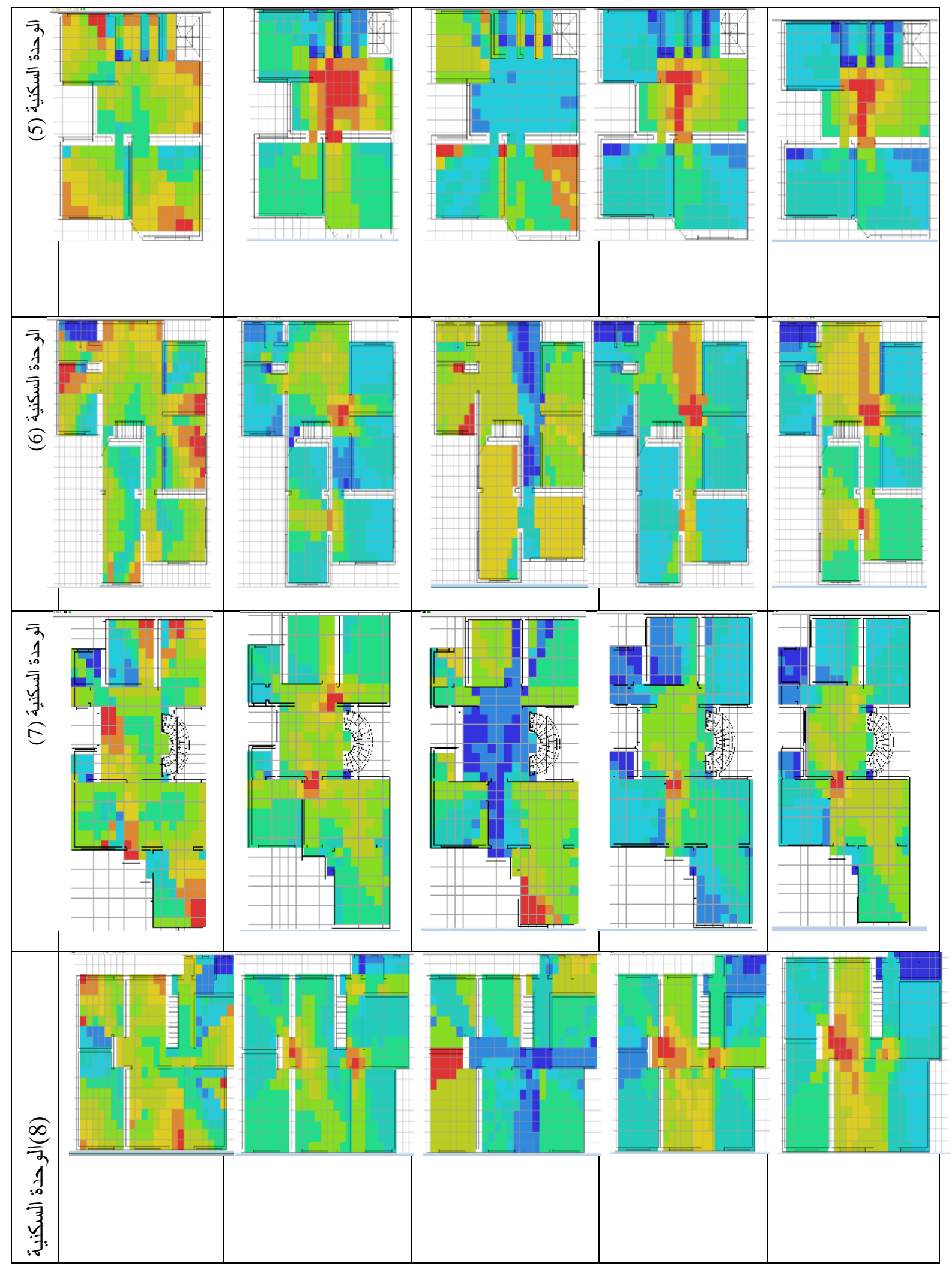


Vol. 23

No. 3

June 2015

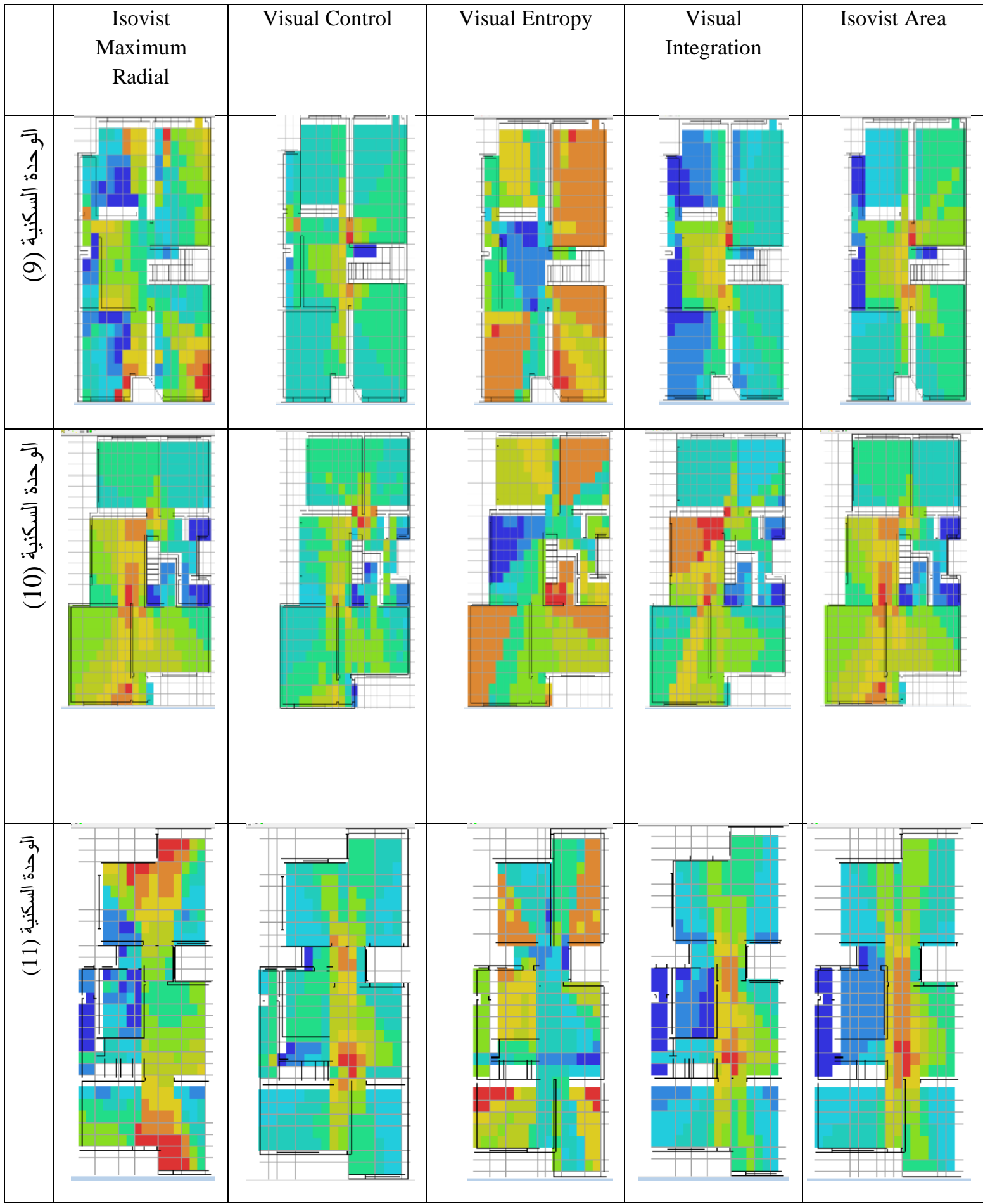

المصدر : برمجية Depth Map 
الدباغ: أثر الخصائص البصرية الفيزياوية للفضاء العائلي على درجة الخيار للفعاليات اليومية ـ المسكن المعاصر ---

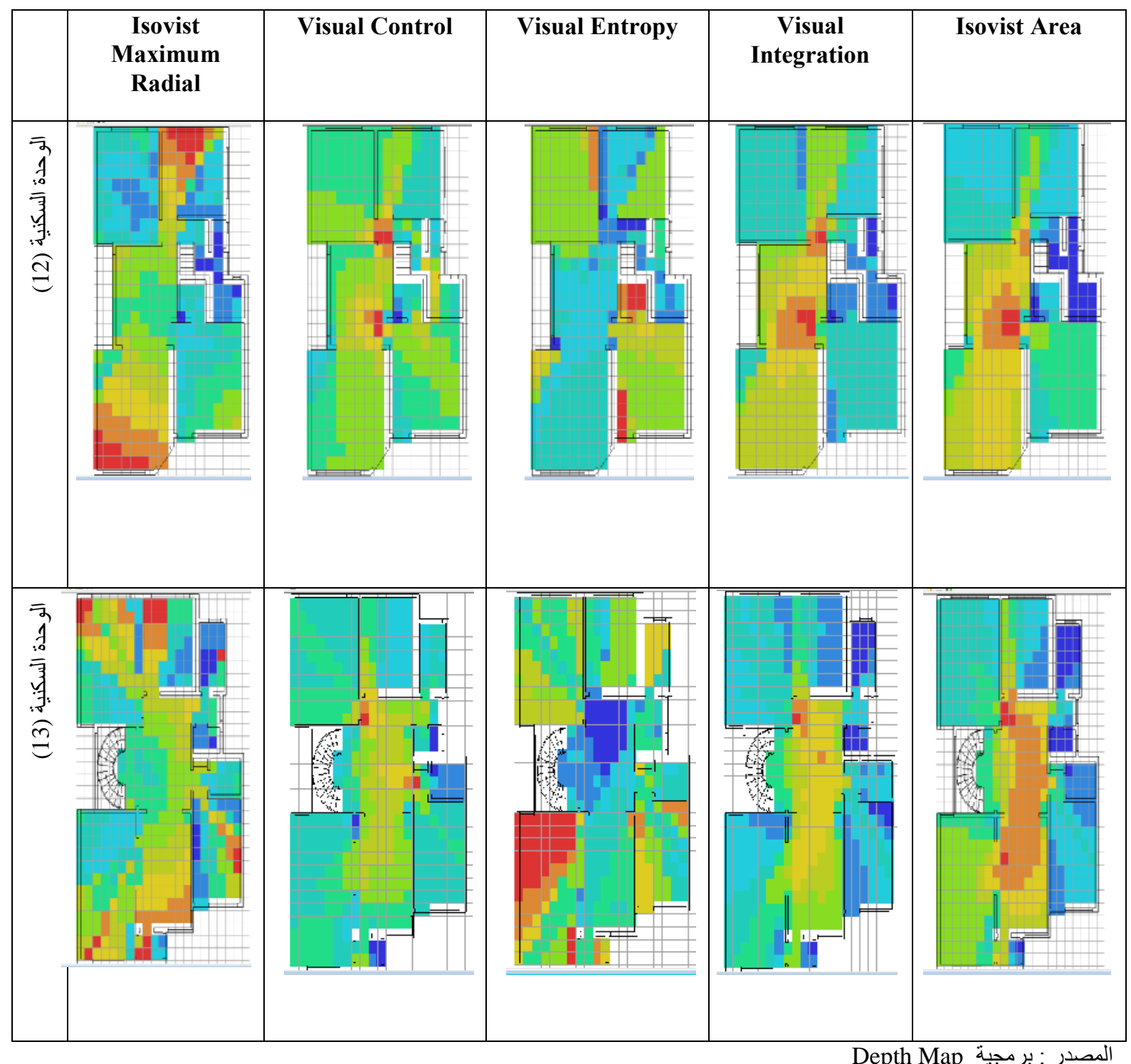

